\title{
Star formation in extreme environments: the effects of cosmic rays and mechanical heating
}

\author{
R. Meijerink ${ }^{1}$, M. Spaans ${ }^{2}$, A. F. Loenen ${ }^{1}$, and P. P. van der Werf ${ }^{1}$ \\ ${ }^{1}$ Leiden Observatory, Leiden University, PO Box 9513, 2300 RA Leiden, The Netherlands \\ e-mail: meijerink@strw.leidenuniv.nl \\ 2 Kapteyn Astronomical Institute, PO Box 800, 9700 AV Groningen, The Netherlands \\ e-mail: spaans@astro.rug.nl
}

Received 2 June 2010 / Accepted 10 October 2010

\begin{abstract}
Context. The molecular interstellar medium in extreme environments, such as Arp 220, but also NGC 253 appears to have extremely high cosmic ray $(\mathrm{CR})$ rates $\left(10^{3}-10^{4} \times\right.$ Milky Way) and substantial mechanical heating from supernova driven turbulence.

Aims. We explore the consequences of high CR rates and mechanical heating on the chemistry of the clouds.

Methods. PDR model predictions are made for low, $n=10^{3}$, and high, $n=10^{5.5} \mathrm{~cm}^{-3}$, density clouds using well-tested chemistry and radiation transfer codes. Column densities of relevant species are discussed, and special attention is given to water-related species. Fluxes are shown for fine-structure lines of $\mathrm{O}, \mathrm{C}^{+}, \mathrm{C}$, and $\mathrm{N}^{+}$, and molecular lines of $\mathrm{CO}, \mathrm{HCN}, \mathrm{HNC}$, and $\mathrm{HCO}^{+}$. A comparison is made with an X-ray dominated region model.

Results. Fine-structure lines of [CII], [CI], and [OI] are remarkably similar for different mechanical heating and $\mathrm{CR}$ rates, when already exposed to large amounts of UV. Both $\mathrm{HCN}$ and $\mathrm{H}_{2} \mathrm{O}$ abundances are boosted for very high mechanical heating rates, while ionized species are relatively unaffected. Both $\mathrm{OH}^{+}$and $\mathrm{H}_{2} \mathrm{O}^{+}$are enhanced for very high CR rates $\zeta \geq 5 \times 10^{-14} \mathrm{~s}^{-1}$. A combination of $\mathrm{OH}^{+}, \mathrm{OH}, \mathrm{H}_{2} \mathrm{O}^{+}, \mathrm{H}_{2} \mathrm{O}$, and $\mathrm{H}_{3} \mathrm{O}^{+}$traces the $\mathrm{CR}$ rates, and is able to distinguish between enhanced cosmic rays and $\mathrm{X}$-rays.
\end{abstract}

Key words. cosmic rays - galaxies: ISM - galaxies: active - galaxies: starburst - ISM: molecules

\section{Introduction}

Observations of molecular tracers imply that both star formation and an active galactic nucleus (AGN, an accreting supermassive black hole) can drive the physics and chemistry of the central $\sim \mathrm{kpc}$ of active galaxies (Sanders \& Mirabel 1996; Gao et al. 1997; Gao \& Solomon 1999; Baan et al. 2008; van der Werf et al. 2010). In particular, ultra-luminous infrared galaxies (ULIRGs), with infrared $(8-1000 \mu \mathrm{m})$ luminosities $L_{\mathrm{IR}} \geq 10^{12} L_{\odot}$, appear to contain large reservoirs of dense, $n>10^{4} \mathrm{~cm}^{-3}$, gas. This gas provides the fuel for (intense) star formation and black hole accretion.

The irradiation by UV photons $(6-13.6 \mathrm{eV}$; creating socalled photon-dominated regions, or PDRs, e.g., Hollenbach \& Tielens 1999) from a starburst or by X-rays (1-100 keV, creating so-called X-ray dominated regions, or XDRs, e.g., Lepp \& Dalgarno 1996; Maloney et al. 1996) from an AGN is expected to produce different signatures in the molecular chemistry (Meijerink \& Spaans 2005; Meijerink et al. 2006, 2007). Mechanical heating due to supernova and stellar outflow driven turbulence has also been explored (Loenen et al. 2008), which shows that warm molecular gas may persist beyond a few magnitudes of extinction in molecular clouds. Furthermore, the radiation feedback from ultraviolet photons, resulting in warm dust of more than $50 \mathrm{~K}$, affect the thermodynamics of the molecular gas, possibly resulting in a top-heavy initial mass function (IMF; Klessen et al. 2007; Hocuk \& Spaans 2010).

The analysis of the physical state of this irradiated gas allows one to constrain the evolutionary state of, ambient star formation rate in, and the importance of feedback for ULIRGs
(Baan et al. 2010). In this work, we focus on the feedback caused by massive stars. In particular, we consider the UV emission from hot stars, the (elevated) production of cosmic rays from the resulting supernova remnants, and the heating produced by turbulent motions driven by travelling supernova blast waves.

A very nice case in point for the feedback effects mentioned above is Arp 220, the proto-typical ULIRG at $77 \mathrm{Mpc}$, which boasts an infrared luminosity of $L_{\mathrm{IR}}=1.3 \times 10^{12} L_{\odot}$ (Soifer et al. 1987). Arp 220 is a merger that contains two nuclei separated by about $370 \mathrm{pc}$ in the east-west direction (e.g., Rodríguez-Rico et al. 2005) and has a nuclear star formation rate of 50-100 $M_{\odot} \mathrm{yr}^{-1}$ (Smith et al. 1998).

Observations of Arp 220 at a resolution of $0.3^{\prime \prime}(100 \mathrm{pc})$ by Sakamoto et al. (2009) indicate P Cygni type profiles in $\mathrm{HCO}^{+}$ 4-3, 3-2 and CO 3-2. These authors interpret their results as a $\sim 100 \mathrm{~km} \mathrm{~s}^{-1}$ outflow driven by supernova explosions (or radiation pressure from the starburst). As many as 49 supernova remnants (SNRs) have been detected with VLBI (1 pc resolution) at $18 \mathrm{~cm}$ (Lonsdale et al. 2006), confirming the formation and demise of many massive stars. The latter authors derive a supernova rate of $3 \mathrm{yr}^{-1}$ for the western nucleus and $1 \mathrm{yr}^{-1}$ for the eastern nucleus, more than two orders of magnitude larger than the entire Milky Way.

Limits on the cosmic ray (CR) rate in our Milky Way are discussed by, e.g., van der Tak \& van Dishoeck (2000). They found a value of $\zeta=2.6 \pm 0.8 \times 10^{-17} \mathrm{~s}^{-1}$ with upper limits that are 3 to 5 times higher. In this paper, we adopt $\zeta=5 \times 10^{-17} \mathrm{~s}^{-1}$ as the canonical Milky Way value. Highly elevated cosmic ray rates are seen in gamma-ray observations of the starburst galaxy NGC 253 (Acero et al. 2009) performed with the High Energy 
Table 1. Model parameters.

\begin{tabular}{llcc}
\hline \hline $\begin{array}{l}\text { Metallicity }\left[Z_{\odot}\right] \\
{[\mathrm{C}]:[\mathrm{O}] \text { ratio }}\end{array}$ & 1.0 & & \\
$\mathrm{CR}$ rates $\left[\mathrm{s}^{-1}\right]$ & $5 \times 10^{-17}, 5 \times 10^{-16}, 5 \times 10^{-15}, 5 \times 10^{-14}, 5 \times 10^{-13}$ \\
\hline Model set & $\begin{array}{c}\text { Density } \\
{\left[\mathrm{cm}^{-3}\right]}\end{array}$ & $\begin{array}{c}\text { Radiation field } \\
{\left[G_{0}\right]}\end{array}$ & $\begin{array}{c}\Gamma_{\text {mech }} \\
{\left[\mathrm{erg} \mathrm{cm}^{-3} \mathrm{~s}^{-1}\right]}\end{array}$ \\
\hline $1 \mathrm{a}$ & $10^{5.5}$ & $10^{5}$ & 0.0 \\
$1 \mathrm{~b}$ & $10^{5.5}$ & $10^{5}$ & $3.0 \times 10^{-18}$ \\
$1 \mathrm{c}$ & $10^{5.5}$ & $10^{5}$ & $2.0 \times 10^{-17}$ \\
2 & $10^{3}$ & $10^{3}$ & 0.0 \\
\hline
\end{tabular}

Stereoscopic System (HESS) array. The observed gamma-ray flux indicates a cosmic ray density that is three orders of magnitude higher than that of our Milky Way.

Papadopoulos (2010) suggests that ULIRGs generally have cosmic ray densities $U_{\mathrm{CR}} \sim 10^{3}-10^{4} U_{\mathrm{CR}, \mathrm{MW}}$, and discusses the impact on the ionization fraction and thermal state of the gas, and the consequences for the initial conditions of star formation. In this paper, we first discuss the detailed effects of enhanced cosmic-ray rates on both the thermal balance and chemistry (Sect. 2). Then, we highlight the global consequences on the chemistry and suggest potential diagnostic species (Sect. 3), which is followed by the observational consequences (Sect. 4). In Sect. 5, we conclude with the key diagnostics needed to derive quantitative and qualitative properties of interstellar medium (ISM) exposed to large amounts of cosmic rays, and show how it differs from those of gas exposed to X-rays.

\section{PDR models}

We constructed a set of PDR models (see Table 1) from the code described by Meijerink \& Spaans (2005) and Meijerink et al. (2007). We consider a low $\left(n=10^{3} \mathrm{~cm}^{-3}\right)$ and a high density $\left(n=10^{5.5} \mathrm{~cm}^{-3}\right.$ ) phase. The low density phase of the ISM is generally not directly connected to star formation. Therefore, the adopted incident UV field in the low density models $\left(G_{0}=10^{3}\right)$ is chosen to be a factor of 100 less intense than the high density phase $\left(G_{0}=10^{5}\right)$ to reflect this and essentially corresponding to models 1 and 4 in Meijerink \& Spaans (2005). We varied the incident cosmic-ray rates between $\zeta=5 \times 10^{-17} \mathrm{~s}^{-1}$ and $\zeta=5 \times 10^{-13} \mathrm{~s}^{-1}$. The highest cosmic-ray rate considered here is two orders of magnitude higher than in Meijerink et al. (2006). We adopt a solar metallicity $Z=Z_{\odot}$ and an abundance ratio $[\mathrm{C}] /[\mathrm{O}]=0.4$, which is based on the average abundances of Asplund et al. (2005) and Jenkins (2004), and summarized in Table 2 of Meijerink \& Spaans (2005) with an updated S depletion (Loenen 2009).

We also consider the effect of mechanical heating in the high density case, specifically $\Gamma_{\text {mech }}=3.0 \times 10^{-18}$ and $2.0 \times$ $10^{-17} \mathrm{erg} \mathrm{cm}^{-3} \mathrm{~s}^{-1}$, which correspond to star formation rates of about $S F R=140$ and $950 M_{\odot} \mathrm{yr}^{-1}$, respectively, for a Salpeter IMF (see Loenen et al. 2008, for details). Mechanical heating is only considered in the high density case, $n=10^{5.5} \mathrm{~cm}^{-3}$, since we expect this dense phase to be directly responsible for star formation and thus be affected directly by the supernovae from massive stars. We assume that the low density phase is only affected by cosmic rays. These are able to travel through large columns $\left(N_{\mathrm{H}} \sim 10^{24} \mathrm{~cm}^{-2}\right)$, since they have small absorption cross-sections, and are likely to impact the ISM on larger scales.

The effects on the thermal balance and chemistry are discussed for model sets $1 \mathrm{a}\left(G_{0}=10^{5} ; n=10^{5.5} \mathrm{~cm}^{-3}\right), 1 \mathrm{~b}$ and $1 \mathrm{c}$ (same as model set $1 \mathrm{a}$, with $\Gamma_{\text {mech }}=3.0 \times 10^{-18}$ and $2.0 \times 10^{-17} \mathrm{erg} \mathrm{cm}^{-3} \mathrm{~s}^{-1}$, respectively $)$, and $2\left(G_{0}=10^{3}\right.$; $n=10^{3} \mathrm{~cm}^{-3}$ ) to highlight the differences between the high and low density phases of the ISM.

\subsection{Thermal balance}

Without boosting the $\mathrm{CR}$ rate (i.e. $\zeta=5 \times 10^{-17} \mathrm{~s}$ ), the surface temperature obtained in the high density model is higher than that of the low density model. This may seem a little counterintuitive, since $G_{0} / n=1(0.3)$ for the low (high) density model, and as a result there is more energy available per particle in the low density model. In addition, cooling is more efficient at high densities. However, for intense radiation fields $\left(G_{0}>10^{4}\right.$, and $\left.n>10^{4}-10^{5} \mathrm{~cm}^{-3}\right)$, the gas cooling thermalizes $(\Lambda \propto n$ instead of $n^{2}$ ), while photo-electric heating becomes more effective because of the higher electron density, and more effective than $\Gamma \sim n$ (e.g., Kaufman et al. 1999; Meijerink et al. 2007).

The sensitivity of the thermal balance to cosmic rays is different for the high and low density phases (see Fig. 1). In model set $1 \mathrm{a}$, only very high $\mathrm{CR}$ rates $\left(\zeta \geq 5 \times 10^{-14} \mathrm{~s}^{-1}\right)$ are able to increase the temperature significantly ( $\sim 25$ to 200 percent) in both the radical region (low $A_{V}$ ) as well as the shielded molecular region. In model sets $1 \mathrm{~b}$ and $1 \mathrm{c}$, mechanical heating in the shielded region of the cloud dominates over cosmic ray heating. Here, the temperatures overlap for all cosmic ray rates, reaching values $T \sim 100-200 \mathrm{~K}$ for model set $1 \mathrm{~b}$ and $T \sim 400 \mathrm{~K}$ for model set $1 \mathrm{c}$. Hence even for moderate mechanical heating rates (in this case corresponding to a $S F R=140 M_{\odot} / \mathrm{yr}$ ), the CR rate has no additional effect on the thermal balance in the shielded regions of clouds. In Model set 2, temperatures increase for higher $\mathrm{CR}$ rates at all column densities, by an order of magnitude at the highest adopted CR rate. The effect on the thermal balance is larger because cooling is simply less efficient at lower densities $\left(\Lambda \propto n^{2}\right)$ than the heating rate, which is proportional to the density $(\Gamma \propto n)$. This ensures that the low density models are more sensitive to a higher heating rate. This is enhanced by the fractional electron abundance also being able to be increased more easily at lower densities $\left(k_{\text {rec }} \propto n^{2}\right)$, resulting in a higher heating efficiency (cf., Bakes \& Tielens 1994), and higher heating rates.

\subsection{Chemical balance}

Electron abundances (Fig. 2): the effect of cosmic rays is less apparent in the unshielded region $\left(N_{\mathrm{H}} \lesssim 3 \times 10^{21} \mathrm{~cm}^{-2}\right)$ than in the molecular region $\left(N_{\mathrm{H}} \gtrsim 10^{22} \mathrm{~cm}^{-2}\right)$ of the cloud, since charged species in the unattenuated part of cloud are also produced by means of the photoionization by the stellar radiation field. Here, the fractional abundance (which is defined as $x_{i}=n_{i} / n\left(\mathrm{H}+2 \mathrm{H}_{2}\right)$ of electrons varies across the range of $x_{\mathrm{e}} \sim 10^{-4}-10^{-3}\left(10^{-4}-10^{-2}\right)$ in the high (low) density models, while the CR rates vary over 4 orders of magnitude. In the molecular region, however, a CR rate that is an order of magnitude higher gives a similar rise in the electron fractional abundance, giving ranges $x_{\mathrm{e}} \sim 10^{-9}-10^{-5}$ and $10^{-7}-10^{-2}$ for the high and low density models, respectively. Adding mechanical heating (1b and 1c) does not change the electron abundance much. The difference in fractional electron abundance between the highest and lowest CR rate is somewhat larger than for the models without mechanical heating.

$\mathrm{H}$ and $\mathrm{H}_{2}$ abundances (Fig. 2): atomic hydrogen is by far the dominant species in the radical region $\left(N_{\mathrm{H}} \lesssim 2-3 \times 10^{21} \mathrm{~cm}^{-2}\right)$, but when the attenuating column becomes larger, molecular 


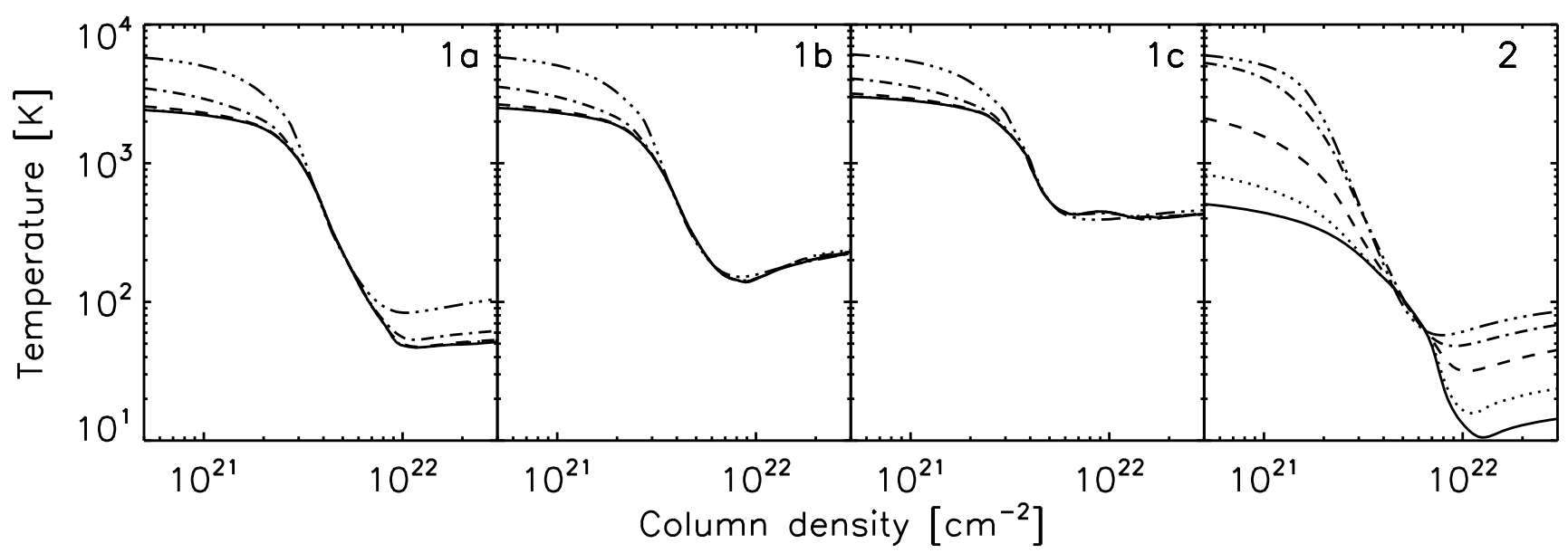

Fig. 1. Temperatures for all models sets (see Table 1) for cosmic ray rates $\zeta=5 \times 10^{-17}$ (solid line), $5 \times 10^{-16}$ (dotted), $5 \times 10^{-15}$ (dashed), $5 \times 10^{-14}$ (dot-dashed), and $5 \times 10^{-13} \mathrm{~s}^{-1}$ (dotted-dashed).

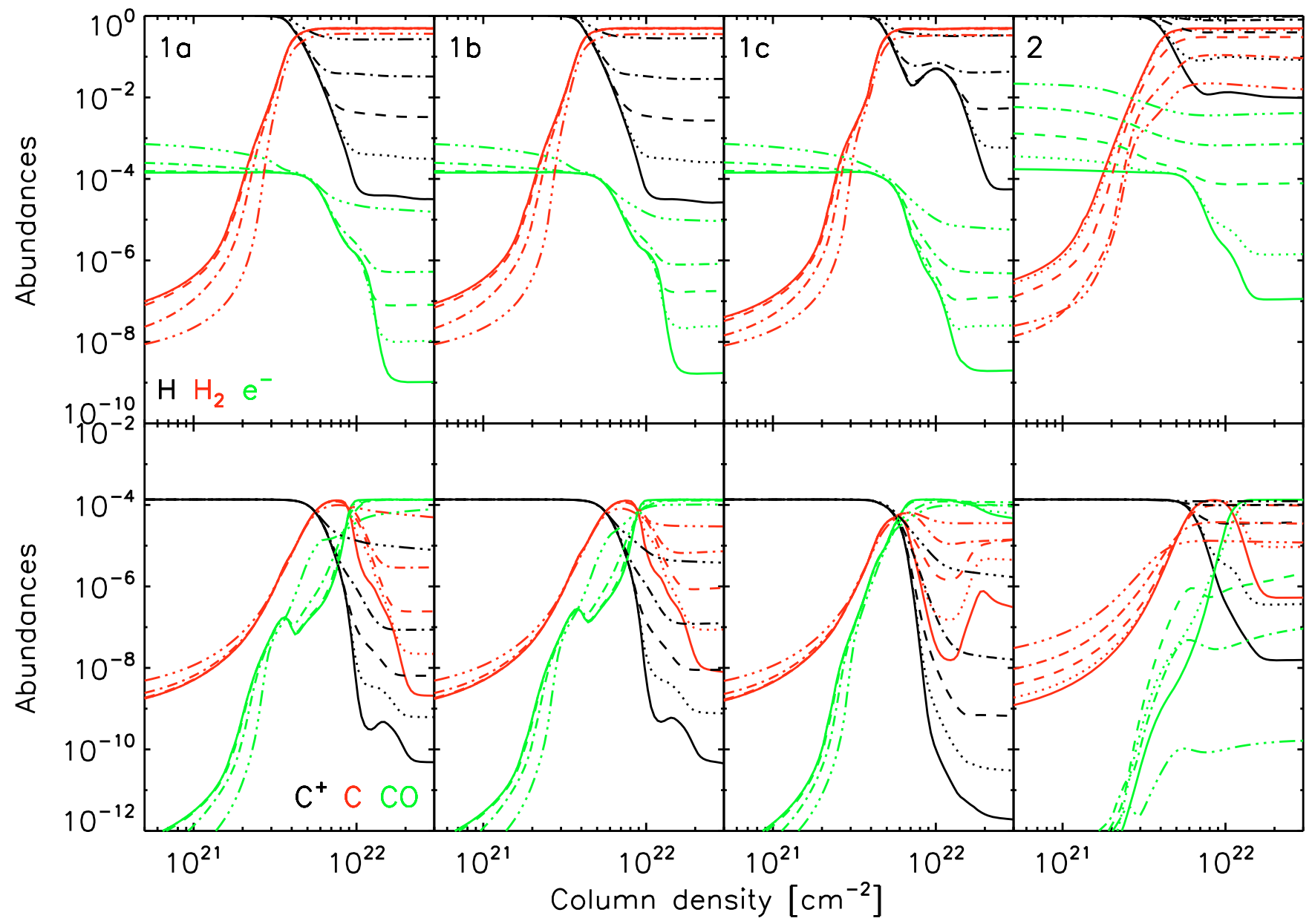

Fig. 2. Abundances of $\mathrm{H}, \mathrm{H}_{2}, \mathrm{e}^{-}, \mathrm{C}^{+}, \mathrm{C}$ and $\mathrm{CO}$ for all models sets (see Table 1). Line styles corresponding to the different $\mathrm{CR}$ rates are the same as in Fig. 1 .

hydrogen becomes more and more abundant. For the canonical CR rate $\left(\zeta=5 \times 10^{-17} \mathrm{~s}^{-1}\right)$, the atomic hydrogen abundance drops below $x_{\mathrm{H}} \sim 10^{-4}\left(10^{-2}\right)$ for the high (low) density models. The $\mathrm{H}$ to $\mathrm{H}_{2}$ transition becomes less and less complete for higher $\mathrm{CR}$ rates, because of $\mathrm{CR}$ reactions such as $\mathrm{H}_{2}+\mathrm{CR} \rightarrow \mathrm{H}+\mathrm{H}^{+}+\mathrm{e}^{-}$ and $\mathrm{H}_{2}+\mathrm{CR} \rightarrow \mathrm{H}_{2}^{+}+\mathrm{e}^{-}$. Atomic and molecular hydrogen are of similar abundance for the highest adopted CR rate in the high density case, while atomic hydrogen is dominant for $\mathrm{CR}$ rates $\zeta>5 \times 10^{-15} \mathrm{~s}^{-1}$ in the low density case.

$\mathrm{C}^{+}, \mathrm{C}$, and $\mathrm{CO}$ abundances (Fig. 2): similar trends are seen for the $\mathrm{C}^{+} / \mathrm{C} / \mathrm{CO}$ transition. For the lowest $\mathrm{CR}$ rate $(\zeta=5 \times$ $\left.10^{-17} \mathrm{~s}^{-1}\right)$, there are three well-defined zones where one species 


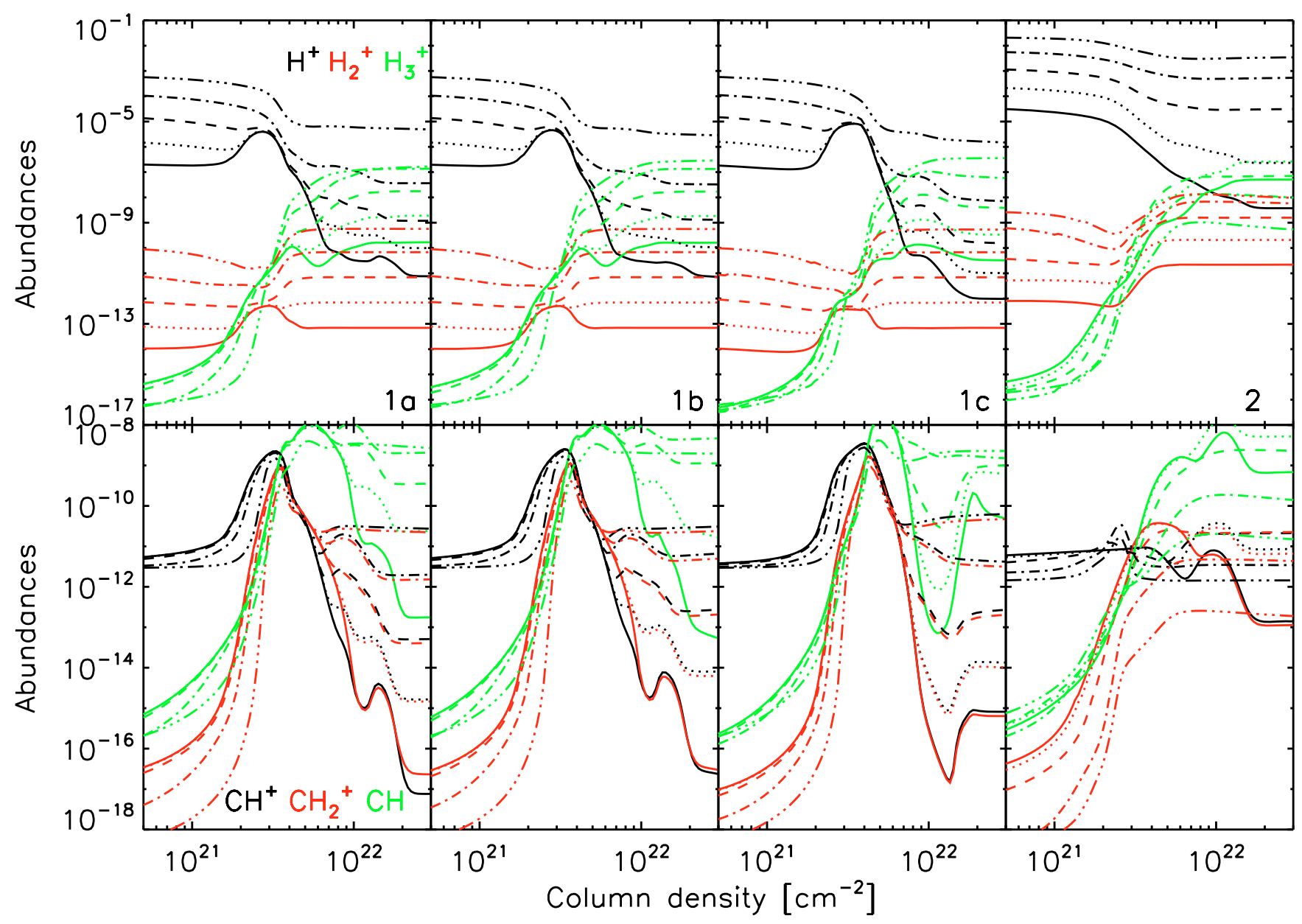

Fig. 3. Abundances of $\mathrm{H}^{+}, \mathrm{H}_{2}^{+}, \mathrm{H}_{3}^{+}, \mathrm{CH}, \mathrm{CH}^{+}$, and $\mathrm{CH}_{2}^{+}$for all model sets (see Table 1). Line styles corresponding to the different $\mathrm{CR}$ rates are the same as in Fig. 1.

is most abundant. Higher CR rates lead to higher neutral carbon abundances in the unattenuated part of the cloud by a factor of $\sim 3(\sim 30)$ in the high (low) density case. However, the abundances are still low compared to that of $\mathrm{C}^{+}$. Again the greatest effect is seen at large column density $\left(N_{\mathrm{H}}>10^{22} \mathrm{~cm}^{-2}\right)$. The $\mathrm{C}^{+}$ and $\mathrm{C}$ abundances increase very rapidly with the $\mathrm{CR}$ rate. In the high density case, the $\mathrm{C}^{+}$and $\mathrm{C}$ abundances become $10^{-6}-10^{-5}$ and $3-6 \times 10^{-5}$, respectively, depending on the amount of additional mechanical heating. There is no full transition to $\mathrm{CO}$ for $\zeta \geq 5 \times 10^{-15} \mathrm{~s}^{-1}$ in the low density case. Neutral carbon is the dominant species at high column density $\zeta=5 \times 10^{-15} \mathrm{~s}^{-1}, \mathrm{C}^{+}$ becomes the dominant species at $\zeta \geq 5 \times 10^{-14} \mathrm{~s}^{-1}$, and at the same time there is almost no CO left $\left(x_{\mathrm{CO}}<10^{-6}\right)$.

$\mathrm{H}^{+}, \mathrm{H}_{2}^{+}$, and $\mathrm{H}_{3}^{+}$abundances (Fig. 3): the main drivers of chemistry in PDRs are ionic species, starting with species $\mathrm{H}^{+}$, $\mathrm{H}_{2}^{+}$, and $\mathrm{H}_{3}^{+}$. Both $\mathrm{H}^{+}$and $\mathrm{H}_{2}^{+}$are mainly (directly or indirectly) produced by cosmic ray ionization $\left(\mathrm{H}+\mathrm{CR} \rightarrow \mathrm{H}^{+}+\mathrm{e}^{-} ; \mathrm{H}_{2}+\right.$ $\mathrm{CR} \rightarrow \mathrm{H}_{2}^{+}+\mathrm{e}^{-}$or $\mathrm{H}^{+}+\mathrm{H}+\mathrm{e}^{-}$or $\left.\mathrm{H}+\mathrm{H}\right)$. UV photons of energy higher than $13.6 \mathrm{eV}$ are all readily absorbed in a very small column, forming an HII region in front of the PDR. $\mathrm{H}_{2}$ can only be photodissociated to two hydrogen atoms (with a UVexcited $\mathrm{H}_{2}^{*}$ as intermediate), no ionic species are produced by direct photoionization of $\mathrm{H}_{2}$. Therefore, the abundances of ionic species are affected significantly by variations in the cosmic ray rate.

In the unshielded region, the abundance increases of $\mathrm{H}^{+}$and $\mathrm{H}_{2}^{+}$scale with the ionization rate. $\mathrm{H}^{+}$is directly produced by cosmic ray ionization. The $\mathrm{H}_{2}^{+}$abundance is balanced by the charge exchange reactions $\mathrm{H}^{+}+\mathrm{H}_{2} \leftrightarrow \mathrm{H}_{2}^{+}+\mathrm{H}$. The reaction to the right has an energy barrier of $T \sim 20000 \mathrm{~K}$, and is only efficient at temperatures of a few thousand Kelvin. Therefore, the $\mathrm{H}_{2}^{+}$abundance may still increase with $\mathrm{CR}$ rate: the lower $\mathrm{H}_{2}$ abundance at higher $\mathrm{CR}$ rates is counteracted by a temperature increase (see Fig. 1). At slightly larger column densities $\left(N_{\mathrm{H}} \sim 3 \times 10^{21} \mathrm{~cm}^{-2}\right)$, the temperature drops and only $\mathrm{H}_{2}^{+}+\mathrm{H} \rightarrow \mathrm{H}^{+}+\mathrm{H}_{2}$ is efficient, while the $\mathrm{H}$ to $\mathrm{H}_{2}$ transition occurs simultaneously. These together result in an abundance maximum of $\mathrm{H}^{+}$, and also explain why the $\mathrm{H}_{2}^{+}$abundance does not increase as rapidly as the $\mathrm{H}_{2}$ abundance.

After the $\mathrm{H}$ to $\mathrm{H}_{2}$ transition $\left(N_{\mathrm{H}} \gtrsim 5 \times 10^{21} \mathrm{~cm}^{-2}\right)$, the overall ionization degree drops, which coincides with a decrease in temperature. This is mostly explained by recombination reactions (e.g., $\mathrm{H}^{+}+\mathrm{e}^{-} \rightarrow \mathrm{H}+$ Photon), which are more efficient at lower temperatures. In this region, the increase in $\mathrm{H}^{+}$with cosmic ray rate is more rapid than linear. The $\mathrm{H}$ to $\mathrm{H}_{2}$ transition is less complete for higher CR rates (Fig. 2), producing a larger reservoir of atomic hydrogen that can potentially be ionized.

$\mathrm{H}_{3}^{+}$is formed and destroyed by $\mathrm{H}_{2}^{+}+\mathrm{H}_{2} \rightarrow \mathrm{H}_{3}^{+}+\mathrm{H}$ and $\mathrm{H}_{3}^{+}+\mathrm{e}^{-} \rightarrow 3 \mathrm{H}$ and $\mathrm{H}_{2}+\mathrm{H}$, respectively. At low column densities, the $\mathrm{H}_{3}^{+}$abundance decreases with $\mathrm{CR}$ rates because of the enhanced electron and reduced $\mathrm{H}_{2}$ abundances. At higher column densities, $\mathrm{H}_{3}^{+}$increases for high $\mathrm{CR}$ rates, but not one to one with the $\mathrm{CR}$ rate, owing to more efficient recombination and lower $\mathrm{H}_{2}$ abundances (especially in the low density models). 


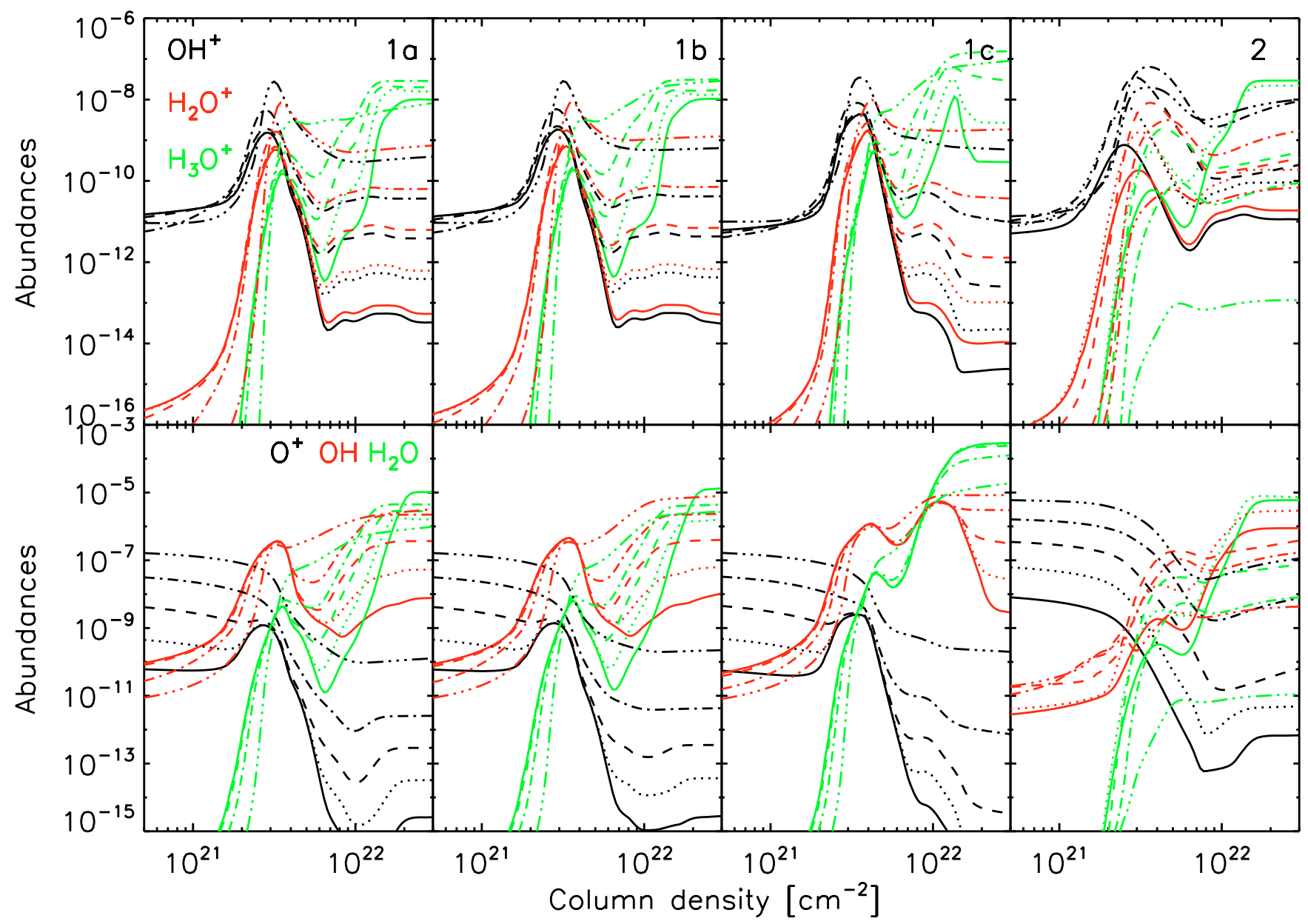

Fig. 4. Abundances of $\mathrm{OH}^{+}, \mathrm{H}_{2} \mathrm{O}^{+}, \mathrm{H}_{3} \mathrm{O}^{+}, \mathrm{O}^{+}, \mathrm{OH}$, and $\mathrm{H}_{2} \mathrm{O}$ for all models sets (see Table 1). Line styles corresponding to the different $\mathrm{CR}$ rates are the same as in Fig. 1.

$\mathrm{CH}^{+}, \mathrm{CH}_{2}^{+}$, and $\mathrm{CH}$ abundances (Fig. 3): in the unshielded region of the cloud, the formation of $\mathrm{CH}^{+}$occurs mainly by means of $\mathrm{C}^{+}+\mathrm{H}_{2}^{*} \rightarrow \mathrm{CH}^{+}+\mathrm{H}$, where $\mathrm{H}_{2}^{*}$ is vibrationally excited molecular hydrogen. Therefore, the $\mathrm{CH}^{+}$abundances do not change much with cosmic ray rate in the unshielded region of the cloud. However, at larger column densities $\left(N_{\mathrm{H}} \sim 10^{22} \mathrm{~cm}^{-2}\right)$, the main route is through $\mathrm{H}_{3}^{+}+\mathrm{C}$. At high density, both the $\mathrm{H}_{3}^{+}$ and $\mathrm{C}$ abundances increase by orders of magnitude for the higher $\mathrm{CR}$ rates, and as a result the $\mathrm{CH}^{+}$abundance as well, despite the higher electron abundance. In the low density case, the $\mathrm{CH}^{+}$ abundances are very similar for all $\mathrm{CR}$ rates because there is no boost now through $\mathrm{C}+\mathrm{H}_{3}^{+}$. The $\mathrm{CH}_{2}^{+}$formation occurs mainly by means of $\mathrm{CH}^{+}+\mathrm{H}_{2} \stackrel{3}{\rightarrow} \mathrm{CH}_{2}^{+}+\mathrm{H}$ and closely follows the abundance of $\mathrm{CH}^{+}$, except where molecular hydrogen is not the dominant species, i.e., in the radical region in the high density case and for very high CR rates in the low density case.

$\mathrm{CH}$ can be formed by the neutral-neutral reactions $\mathrm{C}+\mathrm{H}_{2} \rightarrow$ $\mathrm{CH}+\mathrm{H}$ and $\mathrm{C}+\mathrm{OH} \rightarrow \mathrm{CH}+\mathrm{O}$, which have energy barriers of $T \sim 11700$ and $14800 \mathrm{~K}$, respectively, and the recombination reaction $\mathrm{CH}_{2}^{+}+\mathrm{e}^{-} \rightarrow \mathrm{CH}+\mathrm{H}$. Destruction occurs by means of UV photodissociation and photoionization at small column densities, and by fast charge exchange reactions (e.g., $\mathrm{H}^{+}+\mathrm{CH} \rightarrow \mathrm{CH}^{+}+\mathrm{H}$ ) at all column densities. At small column densities $\left(N_{\mathrm{H}} \lesssim 10^{21} \mathrm{~cm}^{-2}\right)$, the $\mathrm{CH}$ abundances are fairly similar, and UV photoionization dominates the destruction, and neutral-neutral reactions formation. The small differences can be explained by small deviations in $\mathrm{H}_{2}$ and $\mathrm{C}$ abundances. At column densities $N_{\mathrm{H}} \gtrsim 5 \times 10^{21} \mathrm{~cm}^{-2}$, the formation is dominated by the recombination of $\mathrm{CH}_{2}^{+}$, and the abundance is mainly determined by the $\mathrm{CR}$ rate.

Water chemistry (Fig. 4): $\mathrm{H}_{2} \mathrm{O}$ and related species, $\mathrm{OH}^{+}, \mathrm{OH}$, $\mathrm{H}_{2} \mathrm{O}^{+}$, and $\mathrm{H}_{3} \mathrm{O}^{+}$are significantly affected by cosmic rays. First we consider $\mathrm{H}_{2} \mathrm{O}$. It can be formed by the neutral-neutral reaction $\mathrm{H}_{2}+\mathrm{OH} \rightarrow \mathrm{H}_{2} \mathrm{O}+\mathrm{H}$, for which temperatures $T>$ $200-300 \mathrm{~K}$ are required. Cosmic rays are unable to increase the temperature to above this threshold, not even at the highest cosmic ray rates. Another important route, especially when gas is significantly ionized by enhanced cosmic ray rates, is, e.g., $\mathrm{H}_{2}^{+}+\mathrm{O} \rightarrow \mathrm{OH}^{+}+\mathrm{H}$, then $\mathrm{OH}^{+}+\mathrm{H}_{2} \rightarrow \mathrm{H}_{2} \mathrm{O}^{+}+\mathrm{H}$, $\mathrm{H}_{2} \mathrm{O}^{+}+\mathrm{H}_{2} \rightarrow \mathrm{H}_{3} \mathrm{O}^{+}+\mathrm{H}$, followed by recombination, $\mathrm{H}_{3} \mathrm{O}^{+}+$ $\mathrm{e}^{-} \rightarrow \mathrm{H}_{2} \mathrm{O}+\mathrm{H}$. Destruction is possible by UV photodissociation, charge exchange, proton transfer, ion-molecule reactions, and cosmic rays. Important routes are $\mathrm{He}^{+}+\mathrm{H}_{2} \mathrm{O} \rightarrow \mathrm{OH}+\mathrm{He}+\mathrm{H}^{+}$ and $\mathrm{H}^{+}+\mathrm{H}_{2} \mathrm{O} \rightarrow \mathrm{H}_{2} \mathrm{O}^{+}+\mathrm{H}$, and varying the cosmic ray rates affects these abundances. Therefore, at intermediate column densities $N_{\mathrm{H}} \sim 3 \times 10^{21}$ to $10^{22} \mathrm{~cm}^{-2}$ in model sets $1 \mathrm{a}$ and $1 \mathrm{~b}$, the water abundances are higher for higher CR rates. In these models, the temperatures are not high enough to form $\mathrm{H}_{2} \mathrm{O}$ by neutral-neutral reactions. When the temperature is high enough to form water (model set 1c) by the neutral-neutral reactions, a higher ionization degree is a drawback $\left(\mathrm{H}_{2} \mathrm{O}\right.$ is destroyed by, e.g., $\left.\mathrm{He}^{+}\right)$, and the water abundance decreases for very high $\mathrm{CR}$ 


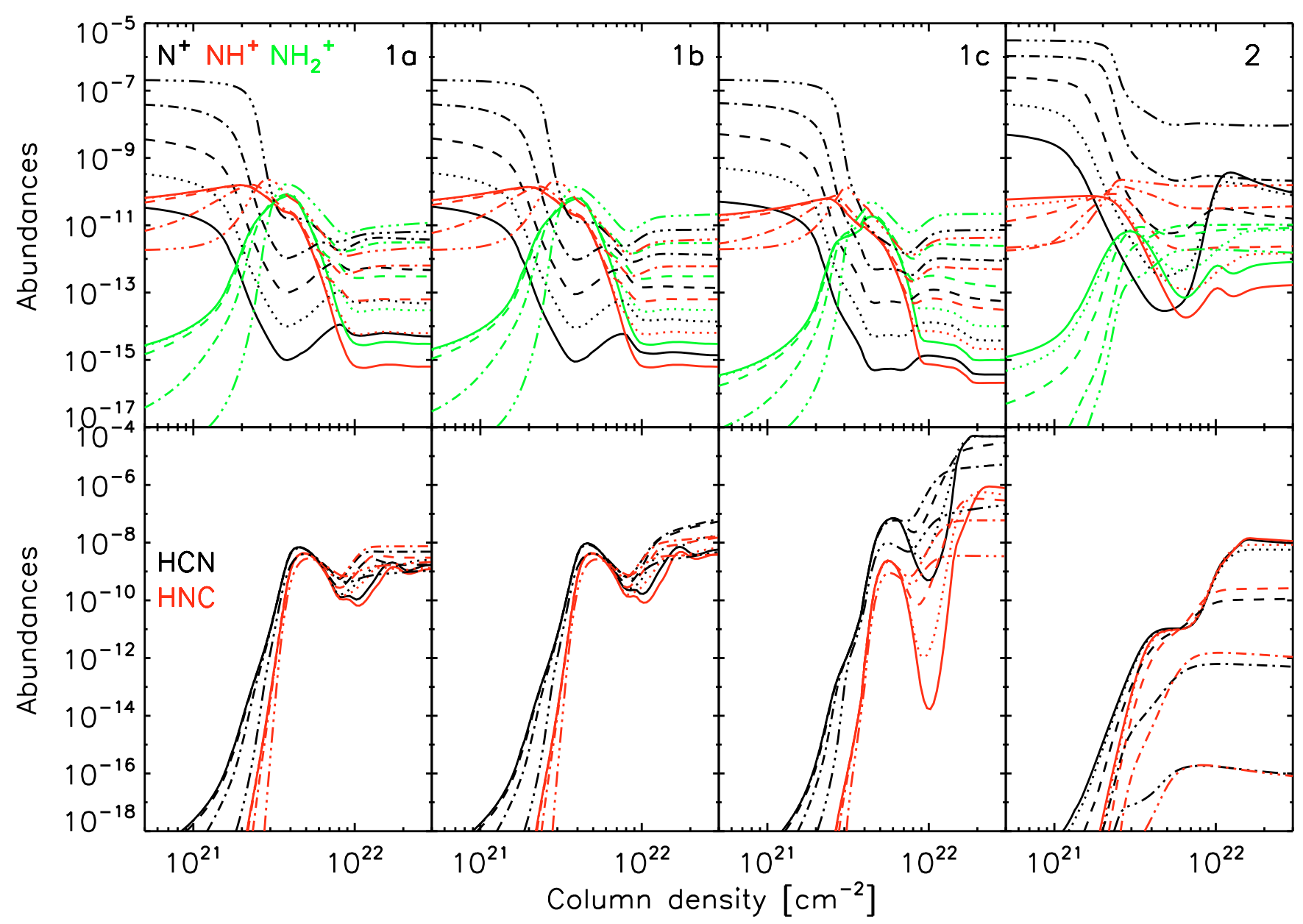

Fig. 5. Abundances of $\mathrm{N}^{+}, \mathrm{NH}^{+}, \mathrm{NH}_{2}^{+}, \mathrm{HCN}$, and $\mathrm{HNC}$ for all models sets (see Table 1). Line styles corresponding to the different $\mathrm{CR}$ rates are the same as in Fig. 1.

rates $\left(\zeta \gtrsim 5 \times 10^{-14} \mathrm{~s}^{-1}\right)$. In model set 2 , there is not enough $\mathrm{H}_{2}$ at the higher cosmic ray rates to form water by ion-molecule reactions.

$\mathrm{OH}$ is formed by $\mathrm{H}_{2}+\mathrm{O} \rightarrow \mathrm{OH}+\mathrm{H}$ or the destruction of water (see previous paragraph). In the radical region where temperatures are significant, formation by neutral reactions dominates. In the high density models, they are closely related to the $\mathrm{H}_{2}$ abundance, and here the $\mathrm{OH}$ abundance is slightly lower for the high $\mathrm{CR}$ rates. In the low density case, the $\mathrm{OH}$ abundance increases with $\mathrm{CR}$ rate in the radical region, since the temperature increases by about an order of magnitude. When temperatures are lower, i.e., at $N_{\mathrm{H}} \gtrsim 5 \times 10^{21} \mathrm{~cm}^{-2}$, the contribution of water destruction becomes more important. $\mathrm{OH}$ abundances are significantly larger in model sets $1 \mathrm{a}$ and $1 \mathrm{~b}$, when CR rates are higher. In model set $1 \mathrm{c}$, formation by neutral-neutral reactions becomes more important, and the effect of an enhanced CR rate less evident.

$\mathrm{OH}^{+}$is formed by $\mathrm{H}^{+}+\mathrm{OH} \rightarrow \mathrm{OH}^{+}+\mathrm{H}$ and $\mathrm{H}^{+}+\mathrm{O} \rightarrow$ $\mathrm{O}^{+}+\mathrm{H}$ followed by $\mathrm{O}^{+}+\mathrm{H}_{2} \rightarrow \mathrm{OH}^{+}+\mathrm{H}$ or by photoionization of $\mathrm{OH}$. At small column densities, where $\mathrm{OH}^{+}$abundances are very similar for different $\mathrm{CR}$ rates, the abundance is determined by the UV ionization of $\mathrm{OH}$. At large column densities $\left(N_{\mathrm{H}} \gtrsim\right.$ $5 \times 10^{21} \mathrm{~cm}^{-2}$ ), the UV is almost completely attenuated, and here the $\mathrm{H}^{+}$driven formation, which is enhanced by cosmic rays, is more important. $\mathrm{H}_{2} \mathrm{O}^{+}$closely follows the $\mathrm{OH}^{+}$abundance at these high column densities. It is mainly formed by $\mathrm{H}_{2}+\mathrm{OH}^{+} \rightarrow$ $\mathrm{H}_{2} \mathrm{O}^{+}+\mathrm{H}$, and also very much higher at higher $\mathrm{CR}$ rates.
Nitrogen chemistry (Fig. 5): $\mathrm{N}^{+}$has an ionization potential of $14.53 \mathrm{eV}$, which is too high for the available UV photons. This species shows orders of magnitude variations for all model sets. The species is strongly affected by the higher cosmic ray rate. $\mathrm{NH}^{+}$and $\mathrm{NH}_{2}^{+}$are closely connected to the cosmic ray rate at high column densities, because the formation is driven by $\mathrm{N}+\mathrm{H}_{2}^{+}$ and $\mathrm{N}^{+}+\mathrm{H}_{2}$.

$\mathrm{HCN}$ and HNC do not show a strong response to enhanced $\mathrm{CR}$ rates in the high density case without mechanical heating, and the abundances remain similar for all $\mathrm{CR}$ rates. Adding mechanical heating (1b), however, drives the $\mathrm{HNC}+\mathrm{H} \rightarrow \mathrm{HCN}+\mathrm{H}$ reaction that has a temperature barrier of $T \sim 200 \mathrm{~K}$, and $\mathrm{HCN}$ has an abundance that is two orders of magnitude higher than HNC. In the low density case (2), both the HCN and HNC abundances, which are similar, decrease rapidly with increasing cosmic ray rates. This is a direct result of the decrease in $\mathrm{H}_{2}$ and $\mathrm{H}_{3}^{+}$, which are important in the formation of these molecules.

$\mathrm{HCO}^{+}$and $\mathrm{CS}$ (Fig. 6): for model sets $1 \mathrm{a}$ and $1 \mathrm{~b}$, the $\mathrm{HCO}^{+}$ abundances are enhanced with increasing CR rates. The formation occurs through $\mathrm{H}_{3}^{+}+\mathrm{CO} \rightarrow \mathrm{HCO}^{+}+\mathrm{H}_{2}$, which is fast at all temperatures, and is aided by $\mathrm{CH}+\mathrm{O} \rightarrow \mathrm{HCO}^{+}+\mathrm{e}^{-}$at high temperatures. Destruction happens by means of recombination with electrons but also reactions with molecules such as $\mathrm{H}_{2} \mathrm{O}, \mathrm{OH}$, and $\mathrm{HCN}$. In model set $1 \mathrm{~b}$, the abundances of these species are especially enhanced for the lower $\left(\zeta=5 \times 10^{-17}\right.$ and $5 \times 10^{-16} \mathrm{~s}^{-1}$ ) cosmic ray rates as discussed in the previous paragraphs, and suppress the $\mathrm{HCO}^{+}$abundance compared 


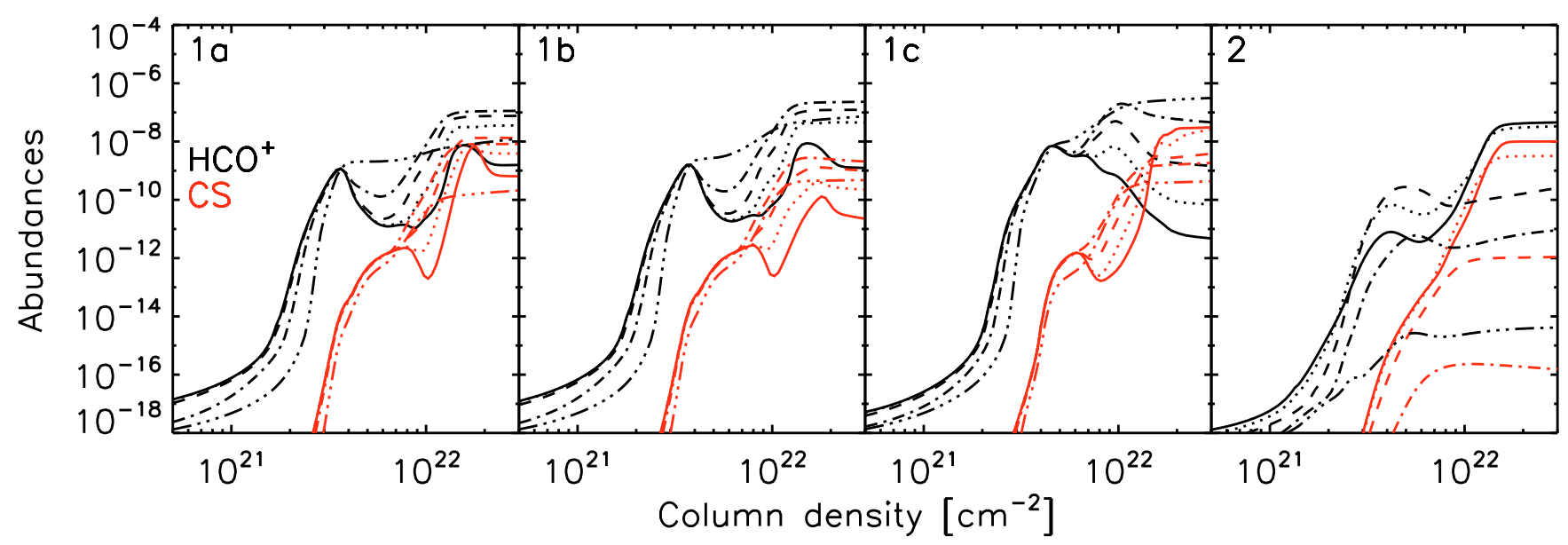

Fig. 6. Abundances of $\mathrm{HCO}^{+}$and $\mathrm{CS}$ for all model sets (see Table 1). Line styles corresponding to the different CR rates are the same as in Fig. 1 .

to the models without mechanical heating. In the low density models (2), where the full transition to $\mathrm{H}_{2}$ does not occur, the $\mathrm{H}_{3}^{+}$abundance is also automatically suppressed, giving smaller abundances with increasing cosmic ray rates.

The sulfur chemistry contains many reactions with activation barriers. CS has two formation channels, the first through $\mathrm{S}+\mathrm{CH} \rightarrow \mathrm{CS}+\mathrm{H}$ and the second through $\mathrm{S}+\mathrm{H}_{2} \rightarrow \mathrm{HS}+\mathrm{H}$ (with an energy barrier of $T \sim 6000 \mathrm{~K}$ ) followed by $\mathrm{HS}+\mathrm{C} \rightarrow \mathrm{CS}+\mathrm{H}$. CS is most abundant at column densities $N_{\mathrm{H}} \gtrsim 5 \times 10^{21} \mathrm{~cm}^{-2}$, where temperatures are not such that the second channel is very effective, although not insignificant in model set 2 . On the other hand, the formation of $\mathrm{CH}$ is dependent on $\mathrm{H}_{3}^{+}$, of which the abundance is highly dependent on $\mathrm{CR}$ rate. Destruction happens through ion-molecule reactions with, e.g., $\mathrm{He}^{+}, \mathrm{H}^{+}, \mathrm{H}_{3}^{+}$, which are also dependent on $\mathrm{CR}$ rate. The abundance is a very complex interplay between temperature and ionization rates (cf., Leen \& Graff 1988; Meijerink et al. 2008). The abundance of CS increases with CR rate in model sets $1 \mathrm{a}$ and $1 \mathrm{~b}$, while model set $1 \mathrm{c}$ exhibits a sharp decline. Molecule formation becomes more and more ineffective in the low density case, and the CS abundance decreases significantly with $\mathrm{CR}$ rate, similar to, e.g., $\mathrm{HCN}$ and HNC.

\section{Integrated column densities}

\subsection{Trends}

The integrated column densities for the total cloud $\left(N_{\mathrm{H}}=3 \times\right.$ $10^{22} \mathrm{~cm}^{-2}$ ) are shown in Tables 2 to 5 for the species discussed in the previous section. The main results are summarized in Fig. 7.

Hydrogen chemistry (top row Fig. 7): the integrated column densities of atomic and molecular hydrogen vary over a factor of 3 (10) for the high (low) density models over the whole range of cosmic ray rates. The ionic species of hydrogen, $\mathrm{H}^{+}$, $\mathrm{H}_{2}^{+}$, and $\mathrm{H}_{3}^{+}$, show much larger variations. The column densities of $N\left(\mathrm{H}^{+}\right)$vary from $\sim 10^{16}-10^{18} \mathrm{~cm}^{-2}\left(10^{17}-10^{20} \mathrm{~cm}^{-2}\right)$ for the high (low density models). $\mathrm{H}_{3}^{+}$increases (decreases) by 4 (2) orders of magnitude in the high (low) density case.

Water chemistry (row 2 and 3 of Fig. 7): the $\mathrm{O}^{+}$column densities are quite strongly correlated with $\mathrm{CR}$ rate, and increase by two to three orders of magnitude over the range of considered CR rates. Although there are large variations in absolute column densities for $\mathrm{OH}$ and $\mathrm{H}_{2} \mathrm{O}$ between the different models, the $\mathrm{OH} / \mathrm{H}_{2} \mathrm{O}$ ratio increases with cosmic ray rate, from
Table 2. Column densities for model set 1a.

\begin{tabular}{llllll}
\hline \hline \multirow{2}{*}{ Species } & \multicolumn{5}{c}{ Cosmic ray rate $\left(\mathrm{s}^{-1}\right)$} \\
& $5(-17)$ & $5(-16)$ & $5(-15)$ & $5(-14)$ & $5(-13)$ \\
\hline \multicolumn{5}{c}{ Column densities $\left(\mathrm{cm}^{-2}\right)$} \\
\hline $\mathrm{H}$ & $4.2(21)$ & $4.2(21)$ & $4.3(21)$ & $5.2(21)$ & $1.2(22)$ \\
$\mathrm{H}_{2}$ & $1.4(22)$ & $1.4(22)$ & $1.4(22)$ & $1.4(22)$ & $1.0(22)$ \\
$\mathrm{H}^{+}$ & $4.9(15)$ & $7.0(15)$ & $2.7(16)$ & $1.9(17)$ & $1.3(18)$ \\
$\mathrm{H}_{2}^{+}$ & $2.7(09)$ & $2.1(10)$ & $2.0(11)$ & $2.0(12)$ & $1.6(13)$ \\
$\mathrm{H}_{3}^{+}$ & $4.1(12)$ & $4.3(13)$ & $4.1(14)$ & $3.2(15)$ & $3.9(15)$ \\
$\mathrm{e}^{-}$ & $8.1(17)$ & $8.1(17)$ & $8.4(17)$ & $1.0(18)$ & $2.5(18)$ \\
$\mathrm{CH}^{+}$ & $2.8(12)$ & $2.7(12)$ & $2.7(12)$ & $2.4(12)$ & $2.0(12)$ \\
$\mathrm{CH}_{2}^{+}$ & $8.7(11)$ & $8.7(11)$ & $8.7(11)$ & $8.4(11)$ & $9.4(11)$ \\
$\mathrm{CH}^{+}$ & $3.1(13)$ & $3.3(13)$ & $5.2(13)$ & $1.1(14)$ & $8.7(13)$ \\
$\mathrm{O}^{+}$ & $6.6(18)$ & $6.4(18)$ & $6.4(18)$ & $6.8(18)$ & $9.3(18)$ \\
$\mathrm{O}^{+}$ & $1.4(12)$ & $2.1(12)$ & $8.2(12)$ & $5.7(13)$ & $3.5(14)$ \\
$\mathrm{OH}^{+}$ & $1.6(12)$ & $1.6(12)$ & $2.1(12)$ & $6.3(12)$ & $3.4(13)$ \\
$\mathrm{H}_{2} \mathrm{O}^{+}$ & $5.1(11)$ & $5.4(11)$ & $8.0(11)$ & $3.3(12)$ & $2.8(13)$ \\
$\mathrm{H}_{3} \mathrm{O}^{+}$ & $1.6(14)$ & $3.1(14)$ & $4.2(14)$ & $6.1(14)$ & $1.7(14)$ \\
$\mathrm{OH}^{+}$ & $5.7(14)$ & $1.5(15)$ & $8.1(15)$ & $4.8(16)$ & $6.7(16)$ \\
$\mathrm{H}_{2} \mathrm{O}$ & $1.4(17)$ & $2.9(16)$ & $5.4(16)$ & $9.1(16)$ & $2.0(16)$ \\
$\mathrm{C}^{+}$ & $7.6(17)$ & $7.6(17)$ & $7.6(17)$ & $7.7(17)$ & $1.0(18)$ \\
$\mathrm{C}$ & $4.7(17)$ & $5.0(17)$ & $5.4(17)$ & $6.3(17)$ & $1.8(18)$ \\
$\mathrm{CO}^{+}$ & $3.2(18)$ & $3.2(18)$ & $3.2(18)$ & $3.1(18)$ & $1.7(18)$ \\
$\mathrm{CO}^{+}$ & $5.7(10)$ & $5.7(10)$ & $5.9(10)$ & $8.3(10)$ & $7.9(11)$ \\
$\mathrm{HCO}^{+}$ & $5.9(13)$ & $6.7(14)$ & $1.5(15)$ & $2.3(15)$ & $2.3(14)$ \\
$\mathrm{N}^{+}$ & $4.0(10)$ & $4.0(11)$ & $4.3(12)$ & $5.0(13)$ & $3.9(14)$ \\
$\mathrm{NH}^{+}$ & $3.5(11)$ & $3.5(11)$ & $3.3(11)$ & $2.9(11)$ & $3.9(11)$ \\
$\mathrm{NH}_{2}^{+}$ & $1.3(11)$ & $1.3(11)$ & $1.4(11)$ & $2.3(11)$ & $5.7(11)$ \\
$\mathrm{HCN}^{+}$ & $4.3(13)$ & $5.7(13)$ & $5.6(13)$ & $1.2(14)$ & $3.2(13)$ \\
$\mathrm{CNC}$ & $2.9(13)$ & $3.5(13)$ & $7.6(13)$ & $1.8(14)$ & $5.0(13)$ \\
\hline & $3.1(13)$ & $8.4(13)$ & $2.5(14)$ & $1.6(14)$ & $3.9(12)$ \\
\hline
\end{tabular}

Notes. Numbers in parentheses: $a(b)=a \times 10^{b}$.

$N(\mathrm{OH}) / N\left(\mathrm{H}_{2} \mathrm{O}\right) \sim 4 \times 10^{-3}(\sim 0.2)$ to $\sim 1-3(\sim 400)$ for the high (low) density models.

The $\mathrm{OH}^{+}$and $\mathrm{H}_{2} \mathrm{O}^{+}$show a strong response to the $\mathrm{CR}$ rate for $\zeta \gtrsim 5 \times 10^{-15} \mathrm{~s}^{-1}$ in the high density case. Above this threshold, the column density increases by a factor $\sim 10-20$ for $\mathrm{OH}^{+}$ and $\sim 50-60$ for $\mathrm{H}_{2} \mathrm{O}^{+}$. In the low density case, the column densities for both species show a steep rise with $\mathrm{CR}$ rate up to $\zeta \sim 5 \times 10^{-14} \mathrm{~s}^{-1}$, after which it levels off for $\mathrm{OH}^{+}$and decreases for $\mathrm{H}_{2} \mathrm{O}^{+}$. The trends of $\mathrm{H}_{3} \mathrm{O}^{+}$generally show an increase (decrease) with $\mathrm{CR}$ rate in the high (low) density case. The response 
Table 3. Column densities for model set $1 \mathrm{~b}$.

\begin{tabular}{|c|c|c|c|c|c|}
\hline \multirow[t]{2}{*}{ Species } & \multicolumn{5}{|c|}{ Cosmic ray rate $\left(\mathrm{s}^{-1}\right)$} \\
\hline & $5(-17)$ & $5(-16)$ & $5(-15)$ & $5(-14)$ & $5(-13)$ \\
\hline \multicolumn{6}{|c|}{ Column densities $\left(\mathrm{cm}^{-2}\right)$} \\
\hline $\mathrm{H}$ & $4.2(21)$ & $4.3(21)$ & $4.3(21)$ & $5.1(21)$ & $1.3(22)$ \\
\hline $\mathrm{H}_{2}$ & $1.4(22)$ & $1.4(22)$ & $1.4(22)$ & $1.4(22)$ & $1.0(22)$ \\
\hline $\mathrm{H}^{+}$ & $5.7(15)$ & $7.9(15)$ & $2.8(16)$ & $2.0(17)$ & $1.3(18)$ \\
\hline $\mathrm{H}_{2}^{+}$ & $2.7(09)$ & $2.1(10)$ & $2.0(11)$ & $2.0(12)$ & $1.6(13)$ \\
\hline $\mathrm{H}_{3}^{+}$ & $4.0(12)$ & $4.2(13)$ & $4.0(14)$ & $3.2(15)$ & $6.7(15)$ \\
\hline $\mathrm{e}^{-3}$ & $8.2(17)$ & $8.2(17)$ & $8.5(17)$ & $1.0(18)$ & $2.3(18)$ \\
\hline $\mathrm{CH}^{+}$ & $3.2(12)$ & $3.2(12)$ & $3.1(12)$ & $2.9(12)$ & $2.3(12)$ \\
\hline $\mathrm{CH}_{2}^{+}$ & $1.0(12)$ & $1.0(12)$ & $1.0(12)$ & $1.0(12)$ & $9.8(11)$ \\
\hline $\mathrm{CH}^{2}$ & $3.1(13)$ & $3.3(13)$ & $7.0(13)$ & $1.6(14)$ & $5.9(13)$ \\
\hline $\mathrm{O}$ & $6.6(18)$ & $6.6(18)$ & $6.7(18)$ & $7.0(18)$ & $8.1(18)$ \\
\hline $\mathrm{O}^{+}$ & $1.7(12)$ & $2.4(12)$ & $8.6(12)$ & $5.8(13)$ & $3.5(14)$ \\
\hline $\mathrm{OH}^{+}$ & $1.9(12)$ & $1.9(12)$ & $2.5(12)$ & $6.9(12)$ & $4.3(13)$ \\
\hline $\mathrm{H}_{2} \mathrm{O}^{+}$ & $6.2(11)$ & $6.5(11)$ & $9.3(11)$ & $3.6(12)$ & $4.2(13)$ \\
\hline $\mathrm{H}_{3} \mathrm{O}^{+}$ & $1.7(14)$ & $2.5(14)$ & $3.5(14)$ & $6.6(14)$ & $6.1(14)$ \\
\hline $\mathrm{OH}$ & $7.2(14)$ & $1.7(15)$ & $8.6(15)$ & $5.1(16)$ & $1.7(17)$ \\
\hline $\mathrm{H}_{2} \mathrm{O}$ & $1.7(17)$ & $2.6(16)$ & $4.9(16)$ & $8.7(16)$ & $5.8(16)$ \\
\hline $\mathrm{C}^{+}$ & $7.7(17)$ & $7.7(17)$ & $7.7(17)$ & $7.8(17)$ & $9.1(17)$ \\
\hline $\mathrm{C}$ & $4.5(17)$ & $4.8(17)$ & $5.3(17)$ & $6.7(17)$ & $1.0(18)$ \\
\hline $\mathrm{CO}$ & $3.2(18)$ & $3.2(18)$ & $3.2(18)$ & $3.0(18)$ & $2.5(18)$ \\
\hline $\mathrm{CO}^{+}$ & $7.4(10)$ & $7.4(10)$ & 7.6(10) & $1.1(11)$ & $1.0(12)$ \\
\hline $\mathrm{HCO}^{+}$ & $6.3(13)$ & $8.9(14)$ & $2.5(15)$ & $4.7(15)$ & $1.4(15)$ \\
\hline $\mathrm{N}^{+}$ & $4.3(10)$ & $4.4(11)$ & $4.6(12)$ & $5.3(13)$ & $4.0(14)$ \\
\hline $\mathrm{NH}^{+}$ & $3.1(11)$ & $3.1(11)$ & $2.9(11)$ & $2.5(11)$ & $3.8(11)$ \\
\hline $\mathrm{NH}_{2}^{+}$ & $1.1(11)$ & $1.1(11)$ & $1.2(11)$ & $2.0(11)$ & $7.3(11)$ \\
\hline $\mathrm{HCN}$ & $1.2(14)$ & $2.8(14)$ & $8.0(14)$ & $9.5(14)$ & $9.0(13)$ \\
\hline HNC & $7.5(13)$ & $1.1(14)$ & $2.5(14)$ & $3.1(14)$ & $8.9(13)$ \\
\hline CS & $8.6(11)$ & $5.2(12)$ & $2.3(13)$ & $5.0(13)$ & $1.0(13)$ \\
\hline
\end{tabular}

Table 4. Column densities for model set 1c.

\begin{tabular}{|c|c|c|c|c|c|}
\hline \multirow[t]{2}{*}{ Species } & \multicolumn{5}{|c|}{ Cosmic ray rate $\left(\mathrm{s}^{-1}\right)$} \\
\hline & $5(-17)$ & $5(-16)$ & $5(-15)$ & $5(-14)$ & $5(-13)$ \\
\hline \multicolumn{6}{|c|}{ Column densities $\left(\mathrm{cm}^{-2}\right)$} \\
\hline $\mathrm{H}$ & $5.1(21)$ & $5.1(21)$ & $5.3(21)$ & $6.2(21)$ & $1.4(22)$ \\
\hline $\mathrm{H}_{2}$ & $1.4(22)$ & $1.4(22)$ & $1.4(22)$ & $1.3(22)$ & $9.3(21)$ \\
\hline $\mathrm{H}^{+}$ & $1.2(16)$ & $1.5(16)$ & $3.8(16)$ & 2.2(17) & $1.4(18)$ \\
\hline $\mathrm{H}_{2}^{+}$ & 2.7(09) & $2.0(10)$ & $2.0(11)$ & $1.9(12)$ & $1.5(13)$ \\
\hline $\mathrm{H}_{3}^{+}$ & $1.5(12)$ & $1.5(13)$ & $1.5(14)$ & $1.9(15)$ & $8.6(15)$ \\
\hline $\mathrm{e}^{-}$ & 7.8(17) & $7.8(17)$ & $8.1(17)$ & $1.0(18)$ & $2.3(18)$ \\
\hline $\mathrm{CH}^{+}$ & $5.7(12)$ & $5.7(12)$ & $5.6(12)$ & $5.5(12)$ & $5.2(12)$ \\
\hline $\mathrm{CH}_{2}^{+}$ & $1.9(12)$ & $1.9(12)$ & $1.9(12)$ & $1.9(12)$ & $2.1(12)$ \\
\hline $\mathrm{CH}^{2}$ & $2.9(13)$ & $3.8(13)$ & $4.5(13)$ & 7.4(13) & $6.2(13)$ \\
\hline $\mathrm{O}$ & $3.2(18)$ & $3.2(18)$ & $3.4(18)$ & $5.1(18)$ & $7.8(18)$ \\
\hline $\mathrm{O}^{+}$ & $3.7(12)$ & $4.4(12)$ & $1.1(13)$ & $6.6(13)$ & $3.9(14)$ \\
\hline $\mathrm{OH}^{+}$ & $5.2(12)$ & $5.3(12)$ & $5.8(12)$ & $1.1(13)$ & $5.9(13)$ \\
\hline $\mathrm{H}_{2} \mathrm{O}^{+}$ & $1.6(12)$ & $1.6(12)$ & $1.8(12)$ & $4.2(12)$ & $6.1(13)$ \\
\hline $\mathrm{H}_{3} \mathrm{O}^{+}$ & $3.3(13)$ & $1.5(14)$ & $8.5(14)$ & $3.2(15)$ & $1.8(15)$ \\
\hline $\mathrm{OH}$ & $3.1(16)$ & $3.2(16)$ & $3.8(16)$ & $8.5(16)$ & $2.1(17)$ \\
\hline $\mathrm{H}_{2} \mathrm{O}$ & $5.3(18)$ & $5.1(18)$ & $4.5(18)$ & $2.3(18)$ & $3.4(17)$ \\
\hline $\mathrm{C}^{+}$ & 7.2(17) & 7.2(17) & 7.2(17) & 7.4(17) & $8.5(17)$ \\
\hline $\mathrm{C}$ & $1.2(17)$ & $1.8(17)$ & $3.4(17)$ & $5.3(17)$ & $1.1(18)$ \\
\hline $\mathrm{CO}$ & 2.3(18) & $2.5(18)$ & $2.9(18)$ & $3.1(18)$ & $2.5(18)$ \\
\hline $\mathrm{CO}^{+}$ & $2.4(11)$ & $2.4(11)$ & $2.4(11)$ & $2.5(11)$ & $9.2(11)$ \\
\hline $\mathrm{HCO}^{+}$ & $1.9(13)$ & $3.9(13)$ & $2.2(14)$ & $1.9(15)$ & $6.4(15)$ \\
\hline $\mathrm{N}^{+}$ & $6.8(10)$ & $6.8(11)$ & $6.9(12)$ & $6.6(13)$ & $4.4(14)$ \\
\hline $\mathrm{NH}^{+}$ & $1.4(11)$ & $1.3(11)$ & $1.3(11)$ & $1.2(11)$ & $2.7(11)$ \\
\hline $\mathrm{NH}_{2}^{+}$ & $3.5(10)$ & $3.5(10)$ & 4.1(10) & $1.0(11)$ & $6.1(11)$ \\
\hline $\mathrm{HCN}$ & $8.0(17)$ & $8.2(17)$ & $4.4(17)$ & $9.5(16)$ & $3.5(15)$ \\
\hline HNC & $1.1(16)$ & $8.0(15)$ & $5.5(15)$ & $1.2(15)$ & $8.0(13)$ \\
\hline CS & 4.6(14) & $3.2(14)$ & $6.3(13)$ & $3.5(13)$ & $8.9(12)$ \\
\hline
\end{tabular}

Table 5. Column densities for model set 2.

\begin{tabular}{|c|c|c|c|c|c|}
\hline \multirow[t]{2}{*}{ Species } & \multicolumn{5}{|c|}{ Cosmic ray rate $\left(\mathrm{s}^{-1}\right)$} \\
\hline & $5(-17)$ & $5(-16)$ & $5(-15)$ & $5(-14)$ & $5(-13)$ \\
\hline \multicolumn{6}{|c|}{ Column densities $\left(\mathrm{cm}^{-2}\right)$} \\
\hline $\mathrm{H}$ & $4.4(21)$ & $6.6(21)$ & $1.6(22)$ & $2.7(22)$ & $3.2(22)$ \\
\hline $\mathrm{H}_{2}$ & $1.4(22)$ & $1.3(22)$ & $8.6(21)$ & $2.8(21)$ & $5.2(20)$ \\
\hline $\mathrm{H}^{+}$ & $5.6(16)$ & $4.2(17)$ & $3.3(18)$ & 2.8(19) & $1.5(20)$ \\
\hline $\mathrm{H}_{2}^{+}$ & $6.3(11)$ & $6.0(12)$ & $4.5(13)$ & $1.8(14)$ & $3.2(14)$ \\
\hline $\mathrm{H}_{3}^{+}$ & $1.1(15)$ & $5.8(15)$ & $1.9(15)$ & $3.1(14)$ & $2.0(13)$ \\
\hline$e^{-}$ & $9.5(17)$ & $1.4(18)$ & $5.5(18)$ & $3.4(19)$ & $1.7(20)$ \\
\hline $\mathrm{CH}^{+}$ & $7.9(10)$ & $4.1(11)$ & $5.8(11)$ & $1.3(11)$ & $5.7(10)$ \\
\hline $\mathrm{CH}_{2}^{+}$ & $1.4(11)$ & $3.9(11)$ & $6.5(11)$ & $1.3(11)$ & $6.1(09)$ \\
\hline $\mathrm{CH}^{-}$ & $4.5(13)$ & $1.7(14)$ & $6.0(13)$ & $4.3(12)$ & $4.7(11)$ \\
\hline $\mathrm{O}$ & $6.8(18)$ & 7.8(18) & $1.1(19)$ & $1.1(19)$ & $1.1(19)$ \\
\hline $\mathrm{O}^{+}$ & $1.3(13)$ & $1.1(14)$ & $6.8(14)$ & $3.8(15)$ & $1.7(16)$ \\
\hline $\mathrm{OH}^{+}$ & $1.2(12)$ & $9.8(12)$ & $5.7(13)$ & $3.0(14)$ & $2.5(14)$ \\
\hline $\mathrm{H}_{2} \mathrm{O}^{+}$ & 7.3(11) & $6.5(12)$ & 2.3(13) & $3.8(13)$ & $1.6(12)$ \\
\hline $\mathrm{H}_{3} \mathrm{O}^{+}$ & $5.7(14)$ & $4.3(14)$ & $1.4(13)$ & $1.8(12)$ & $3.0(09)$ \\
\hline $\mathrm{OH}$ & $1.8(16)$ & $5.9(16)$ & $7.5(15)$ & $3.3(15)$ & $1.0(14)$ \\
\hline $\mathrm{H}_{2} \mathrm{O}$ & 1.1(17) & $1.5(17)$ & $1.6(15)$ & $1.7(14)$ & $2.7(11)$ \\
\hline $\mathrm{C}^{+}$ & $8.4(17)$ & $8.7(17)$ & $1.8(18)$ & $3.5(18)$ & $4.1(18)$ \\
\hline $\mathrm{C}$ & $6.8(17)$ & $9.3(17)$ & $2.6(18)$ & $9.9(17)$ & $3.6(17)$ \\
\hline $\mathrm{CO}$ & $2.9(18)$ & $2.7(18)$ & $4.0(16)$ & $1.8(15)$ & $3.9(12)$ \\
\hline $\mathrm{CO}^{+}$ & 7.8(09) & $7.3(10)$ & $2.9(11)$ & $2.4(11)$ & 4.3(09) \\
\hline $\mathrm{HCO}^{+}$ & $8.2(14)$ & $6.0(14)$ & $5.0(12)$ & $1.7(11)$ & $9.7(07)$ \\
\hline $\mathrm{N}^{+}$ & $9.5(12)$ & $4.8(13)$ & $3.4(14)$ & $2.0(15)$ & $6.9(15)$ \\
\hline $\mathrm{NH}^{+}$ & $1.8(11)$ & $1.8(11)$ & $2.2(11)$ & $1.3(12)$ & $4.8(12)$ \\
\hline $\mathrm{NH}_{2}^{+}$ & $2.6(10)$ & $1.6(11)$ & $2.3(11)$ & $3.0(11)$ & $4.9(10)$ \\
\hline $\mathrm{HCN}$ & $2.2(14)$ & $1.2(14)$ & $2.6(12)$ & $1.5(10)$ & $3.5(06)$ \\
\hline HNC & $2.5(14)$ & $1.8(14)$ & 6.1(12) & $3.4(10)$ & $3.3(06)$ \\
\hline CS & $1.8(14)$ & $6.2(13)$ & $2.5(10)$ & $4.9(06)$ & $3.2(03)$ \\
\hline
\end{tabular}

is more direct when high mechanical heating is added and temperatures are higher.

$\mathrm{CO}^{+}$and $\mathrm{HCO}^{+}$(row 4 in Fig. 7): $\mathrm{HCO}^{+}$does not show an obvious trend with increasing $\mathrm{CR}$ rates in the high density case. The $\mathrm{HCO}^{+}$abundance anti-correlates with $\mathrm{CR}$ rate in the low density case. It does not seem to be a tracer that can be easily used as a CR tracer, but it does provide information when used in combination with e.g. the water chemistry. $\mathrm{CO}^{+}$is very irresponsive to the $\mathrm{CR}$ rates at high density except for very high $\mathrm{CR}$ rates $\left(\zeta>5 \times 10^{-14} \mathrm{~s}^{-1}\right)$. In the low density case, $N\left(\mathrm{CO}^{+}\right)$does not show a very obvious trend.

$\mathrm{C}^{+}, \mathrm{N}^{+}$, and $\mathrm{C}$ (bottom row in Fig. 7): neutral and singly ionized carbon have very constant column densities over the range of $\mathrm{CR}$ rates considered. On the other hand, $\mathrm{N}^{+}$correlates very well with the $C R$ rates, and hence the $\mathrm{N}^{+} / \mathrm{C}$ or $\mathrm{N}^{+} / \mathrm{C}^{+}$column density ratio can be used as a diagnostic in estimating the $\mathrm{CR}$ rate.

Other species: despite many species exhibiting large local variations in a cloud when varying CR rates, it does not always result in significant changes in the integrated column densities in high density clouds. Examples are $\mathrm{CH}^{+}$and $\mathrm{CH}_{2}^{+}$which are the same within five percent over the whole range. In the low density models, variations are larger, but the integrated column densities are one or two orders of magnitude smaller. There are also species that are not easy to interpret, such as $\mathrm{NH}^{+}, \mathrm{NH}_{2}^{+}$, and CS.

\subsection{Uncertainties}

Molecular hydrogen, $\mathrm{H}_{2}$, is a key species in the chemistry of the ISM. The formation of $\mathrm{H}_{2}$, which mainly occurs on grain surfaces at these densities and metallicity, depends on the specific properties and temperatures of the grains, and is subject 


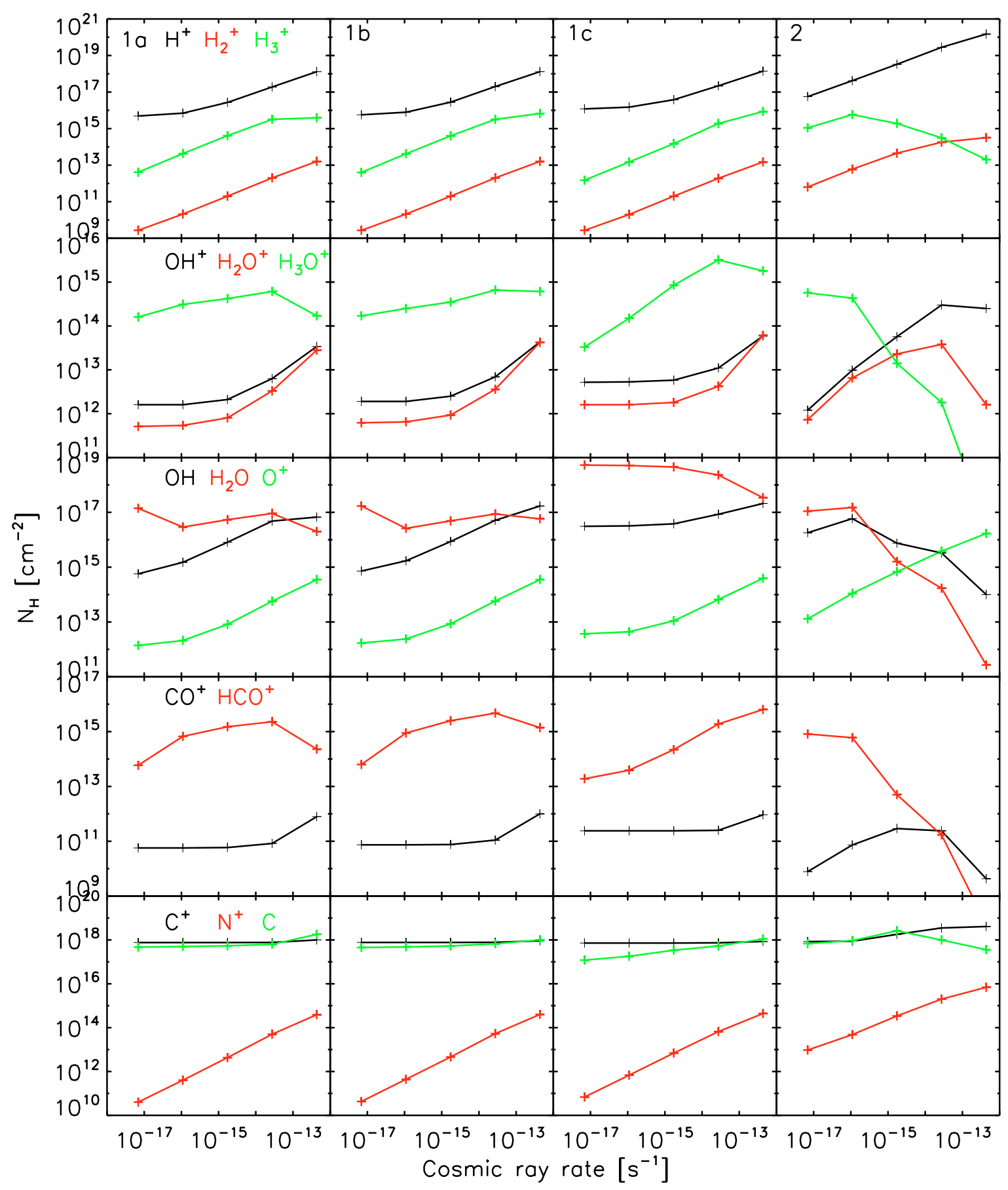

Fig. 7. Column densities of diagnostic species.

to considerable uncertainty (cf., Cazaux \& Tielens 2004). As a result the $\mathrm{H}_{2}$ gas phase abundance is also uncertain, especially when the gas is not predominantly molecular, i.e., in the radical region.

Therefore, the column densities of key species such as $\mathrm{O}^{+}$, $\mathrm{OH}, \mathrm{OH}^{+}$, and $\mathrm{H}_{2} \mathrm{O}^{+}$might be affected, especially when the integrated column density is dominated by the abundances in the radical region. To investigate this, we lowered the $\mathrm{H}_{2}$ formation rate by a factor 3 , and here we summarize the results for some of the species, considering model set $1 \mathrm{a}$ :

$\mathrm{H}_{2}, \mathrm{H}_{2}^{+}$, and $\mathrm{H}^{+}$: the abundance of $\mathrm{H}_{2}$ is lower by a factor of $\sim 3$ in the unshielded region of the cloud, and the $\mathrm{H}$ to $\mathrm{H}_{2}$ transition occurs now more gradually. In the molecular region, there is only a noticeable effect when there is no full transition to $\mathrm{H}_{2}$, which is for the highest considered CR rate, $\zeta=5 \times 10^{-13} \mathrm{~s}^{-1}$. The column density of atomic hydrogen is $\sim 10$ percent higher for the lowest up to $\sim 80$ percent higher for the highest CR rate. Molecular hydrogen column densities only change significantly for the two highest CR rates, becoming $\sim 20$ and $\sim 40$ percent lower, respectively.

The $\mathrm{H}^{+}$column density is lower by a factor $\sim 3$ for the lowest and $\sim 5$ to $\sim 15$ percent higher for the highest two $\mathrm{CR}$ rates. The $\mathrm{H}^{+}$column density is dominated by $\mathrm{H}_{2}^{+}+\mathrm{H} \rightarrow \mathrm{H}^{+}+\mathrm{H}_{2}$ in the radical region at $\zeta=5 \times 10^{-17} \mathrm{~s}^{-1}$ and thus lower, while at higher 
CR rates the column density is higher because of the only partial transition to $\mathrm{H}_{2}$

$\mathrm{O}^{+}, \mathrm{OH}, \mathrm{OH}^{+}, \mathrm{H}_{2} \mathrm{O}$ and $\mathrm{H}_{2} \mathrm{O}^{+}$, and $\mathrm{H}_{3} \mathrm{O}^{+}$: the trend seen for the $\mathrm{O}^{+}$column density is very close to what is seen for $\mathrm{H}^{+}$, i.e, a factor of $\sim 3$ lower for $\zeta=5 \times 10^{-17} \mathrm{~s}^{-1}$, while slightly higher for the highest $\mathrm{CR}$ rates. Similar trends are seen for $\mathrm{OH}^{+}$and $\mathrm{H}_{2} \mathrm{O}^{+}$.

$\mathrm{H}_{2} \mathrm{O}$ is only significantly affected (lowered by a factor $\sim 2$ ) at the highest $\mathrm{CR}$ rate. $\mathrm{OH}$ column density is lower by a factor $\sim 3$ for the lowest CR rates, and dominated by the abundance in the unshielded region of the cloud. This difference is much less (5-30 percent) for the higher $\mathrm{CR}$ rates. $\mathrm{H}_{2} \mathrm{O}$ and $\mathrm{H}_{3} \mathrm{O}^{+}$column densities are only affected for the highest two $\mathrm{CR}$ rates.

In all, we conclude that the overall trends are not affected by uncertainties in the $\mathrm{H}_{2}$ abundance, the main driver of the species of interest in our paper. The largest changes are seen when the integrated column density of a species is dominated by its abundance in the radical region, i.e., in the models with low $\mathrm{CR}$ rates.

\section{Integrated line fluxes}

Line fluxes for a number of species discussed in the previous section are shown in Tables 6 to 9. Here we highlight the main results:

Fine-structure lines: the two important cooling lines, [OI] $63 \mu \mathrm{m}$ and [CII] $158 \mu \mathrm{m}$, which mainly determine the energy budget of interstellar clouds, have very similar fluxes for different $\mathrm{CR}$ rates in the high density case. [OI] $63 \mu \mathrm{m}$ is the same within a factor of 2 in the high density case for all mechanical heating and $\mathrm{CR}$ rates, but does increase by a factor of 5 in the low density case. The critical density for excitation of the [OI] $63 \mu \mathrm{m}$ is $n_{\text {crit }}=5 \times 10^{5} \mathrm{~cm}^{-3}$, and the low density model is not even close to being thermalized, and temperature differences cause a large change in emitted flux. The [CII] $158 \mu \mathrm{m}$ has a very low critical density $n_{\text {crit }}=2.8 \times 10^{3} \mathrm{~cm}^{-3}$, and the increase in fluxes is not explained by the rise in temperature at small column densities. Additional flux is emitted in low density clouds, because there is no full transition to neutral carbon and $\mathrm{CO}$, for the highest $\mathrm{CR}$ rates (see Sect. 2). This also explains why the two neutral carbon lines, [CI] $610 \mu \mathrm{m}$ and [CI] $370 \mu \mathrm{m}$, show an increase in the high density models. The low density models have a maximum intensity at $\zeta \sim 5 \times 10^{-15} \mathrm{~s}^{-1}$, since for higher $\mathrm{CR}$ rates the main carbon budget remains in $\mathrm{C}^{+}$. The two ionized nitrogen lines, [NII] $205 \mu \mathrm{m}$ and [NII] $122 \mu \mathrm{m}$, increase by 4 (3) orders of magnitude in the high (low) density case. Low density clouds, in particular, are expected to yield detectable fluxes: the [NII] $122 \mu \mathrm{m}$ lines has only a 10 times weaker flux than the [CII] line at the highest $\mathrm{CR}$ rate. Unfortunately, $\mathrm{O}^{+}$does not have finestructure transitions in the mid and far-infrared. Available transitions are in the visible and UV, and have very high excitation energies.

$H_{3}^{+} 95 \mu m$ : this transition is calculated following the discussion in Pan \& Oka (1986). The fluxes in the high density case are very similar to the [NII] $122 \mu \mathrm{m}$, not extremely strong, but potentially detectable, when clouds are exposed to very high CR fluxes.

$\mathrm{HCN}, \mathrm{HNC}$, and $\mathrm{HCO}^{+}$: the $\mathrm{HCN}$ and $\mathrm{HNC}$ do not seem to be very helpful in the discussion of cosmic ray rates, as there are no obvious trends. The $\mathrm{HCN} / \mathrm{HNC}$ ratio does show a response to mechanical heating as already pointed out in Loenen et al. (2008), and HCN in particular is boosted by a few orders of magnitude. An exception is the high density with the high CR rate, where $\mathrm{He}^{+}$destroys the $\mathrm{HCN}$ and $\mathrm{HNC}$ very effectively. In addition, $\mathrm{HCO}^{+}$does not exhibit very obvious trends, except for very high mechanical heating rates (model set $1 \mathrm{c}$ ).
Table 6. Line intensities for model set 1a.

\begin{tabular}{|c|c|c|c|c|c|}
\hline \multirow[t]{2}{*}{ Line } & \multicolumn{5}{|c|}{ Cosmic ray rate $\left(\mathrm{s}^{-1}\right)$} \\
\hline & $5(-17)$ & $5(-16)$ & $5(-15)$ & $5(-14)$ & $5(-13)$ \\
\hline \multicolumn{6}{|c|}{ Line intensities $\left(\mathrm{erg} \mathrm{s}^{-1} \mathrm{~cm}^{-2} \mathrm{sr}^{-1}\right)$} \\
\hline [CII] $158 \mu \mathrm{m}$ & $1.1(-3)$ & $1.1(-3)$ & $1.1(-3)$ & $1.1(-3)$ & $1.3(-3)$ \\
\hline$[\mathrm{CI}] 610 \mu \mathrm{m}$ & $3.7(-6)$ & $3.9(-6)$ & $4.2(-6)$ & $4.8(-6)$ & $1.1(-5)$ \\
\hline [CI] $370 \mu \mathrm{m}$ & 2.1(-5) & $2.2(-5)$ & $2.3(-5)$ & $2.6(-5)$ & $6.2(-5)$ \\
\hline [OI] $63 \mu \mathrm{m}$ & $7.8(-2)$ & $7.8(-2)$ & $7.8(-2)$ & $8.2(-2)$ & $9.2(-2)$ \\
\hline [OI] $146 \mu \mathrm{m}$ & $2.3(-3)$ & $2.3(-3)$ & $2.3(-3)$ & $2.4(-3)$ & $2.9(-3)$ \\
\hline [NII] $205 \mu \mathrm{m}$ & $4.4(-11)$ & $4.4(-10)$ & 4.7(-9) & $5.5(-8)$ & $4.2(-7)$ \\
\hline [NII] $122 \mu \mathrm{m}$ & $6.6(-10)$ & $6.6(-9)$ & 7.1(-8) & $8.4(-7)$ & $6.6(-6)$ \\
\hline $\mathrm{H}_{3}^{+} 95 \mu \mathrm{m}$ & $7.0(-10)$ & $6.2(-9)$ & $6.0(-8)$ & $6.5(-7)$ & $1.9(-6)$ \\
\hline $\mathrm{HCN} J=1-0$ & $1.5(-8)$ & $1.8(-8)$ & $1.8(-8)$ & $2.9(-8)$ & $1.1(-8)$ \\
\hline $\mathrm{HCN} J=2-1$ & $1.3(-7)$ & $1.5(-7)$ & $1.5(-7)$ & $2.2(-7)$ & $1.3(-7)$ \\
\hline $\mathrm{HCN} J=3-2$ & $3.2(-7)$ & $3.7(-7)$ & $3.6(-7)$ & $5.8(-7)$ & $3.3(-7)$ \\
\hline $\mathrm{HCN} J=4-3$ & $3.8(-7)$ & $4.7(-7)$ & $4.5(-7)$ & $8.9(-7)$ & $4.4(-7)$ \\
\hline $\mathrm{HCN} J=5-4$ & $3.3(-7)$ & $4.0(-7)$ & $3.9(-7)$ & 7.7(-7) & $4.0(-7)$ \\
\hline $\mathrm{HCN} J=6-5$ & $2.6(-7)$ & $3.0(-7)$ & $3.0(-7)$ & $5.2(-7)$ & $3.1(-7)$ \\
\hline $\mathrm{HCN} J=7-6$ & $2.0(-7)$ & $2.2(-7)$ & $2.2(-7)$ & $3.2(-7)$ & $2.2(-7)$ \\
\hline HNC $J=1-0$ & $1.1(-8)$ & $1.3(-8)$ & $2.0(-8)$ & $3.6(-8)$ & $1.7(-8)$ \\
\hline HNC $J=2-1$ & $9.9(-8)$ & $1.1(-7)$ & $1.6(-7)$ & $2.5(-7)$ & $1.7(-7)$ \\
\hline HNC $J=3-2$ & $2.1(-7)$ & $2.4(-7)$ & $3.9(-7)$ & $6.7(-7)$ & $4.5(-7)$ \\
\hline HNC $J=4-3$ & $2.3(-7)$ & $2.6(-7)$ & $4.9(-7)$ & $1.1(-6)$ & $6.3(-7)$ \\
\hline HNC $J=5-4$ & $1.9(-7)$ & $2.0(-7)$ & $3.4(-7)$ & $1.1(-6)$ & $5.7(-7)$ \\
\hline HNC $J=6-5$ & $1.4(-7)$ & $1.5(-7)$ & $2.2(-7)$ & $6.1(-7)$ & $4.2(-7)$ \\
\hline HNC $J=7-6$ & $9.7(-8)$ & $1.0(-7)$ & $1.3(-7)$ & $3.3(-7)$ & $2.8(-7)$ \\
\hline $\mathrm{HCO}^{+} J=1-0$ & $2.7(-8)$ & $1.0(-7)$ & $1.5(-7)$ & $1.6(-7)$ & $5.5(-8)$ \\
\hline $\mathrm{HCO}^{+} J=2-1$ & $2.8(-7)$ & 7.7(-7) & $9.8(-7)$ & $1.2(-6)$ & 7.3(-7) \\
\hline $\mathrm{HCO}^{+} J=3-2$ & $8.1(-7)$ & $2.2(-6)$ & $2.7(-6)$ & $3.3(-6)$ & $3.1(-6)$ \\
\hline $\mathrm{HCO}^{+} J=4-3$ & $1.4(-6)$ & $4.4(-6)$ & $5.5(-6)$ & $6.8(-6)$ & $6.8(-6)$ \\
\hline $\mathrm{HCO}^{+} J=5-4$ & $1.6(-6)$ & $7.2(-6)$ & $9.4(-6)$ & $1.2(-5)$ & $9.4(-6)$ \\
\hline $\mathrm{HCO}^{+} J=6-5$ & $1.2(-6)$ & $1.0(-5)$ & $1.4(-5)$ & $1.9(-5)$ & $1.3(-5)$ \\
\hline $\mathrm{HCO}^{+} J=7-6$ & $8.2(-7)$ & $1.2(-5)$ & $2.0(-5)$ & $2.8(-5)$ & $1.5(-5)$ \\
\hline $\operatorname{CO} J=1-0$ & $3.0(-7)$ & $3.0(-7)$ & $3.1(-7)$ & $3.2(-7)$ & $3.1(-7)$ \\
\hline $\operatorname{CO} J=2-1$ & $2.9(-6)$ & $3.0(-6)$ & $3.0(-6)$ & $3.3(-6)$ & $3.9(-6)$ \\
\hline $\mathrm{CO} J=3-2$ & $1.0(-5)$ & $1.0(-5)$ & $1.1(-5)$ & $1.2(-5)$ & $1.5(-5)$ \\
\hline $\operatorname{CO} J=4-3$ & $2.4(-5)$ & $2.4(-5)$ & $2.5(-5)$ & $2.8(-5)$ & $3.9(-5)$ \\
\hline $\mathrm{CO} J=5-4$ & $4.3(-5)$ & $4.4(-5)$ & $4.6(-5)$ & $5.3(-5)$ & $7.8(-5)$ \\
\hline $\operatorname{CO} J=6-5$ & $6.7(-5)$ & $6.8(-5)$ & 7.1(-5) & $8.4(-5)$ & $1.3(-4)$ \\
\hline $\mathrm{CO} J=7-6$ & $9.2(-5)$ & $9.4(-5)$ & $9.8(-5)$ & $1.2(-4)$ & $2.0(-4)$ \\
\hline $\operatorname{CO} J=8-7$ & $1.1(-4)$ & $1.1(-4)$ & $1.2(-4)$ & $1.5(-4)$ & $2.8(-4)$ \\
\hline $\mathrm{CO} J=9-8$ & $1.2(-4)$ & $1.3(-4)$ & $1.3(-4)$ & $1.7(-4)$ & $3.6(-4)$ \\
\hline $\mathrm{CO} J=10-9$ & $1.1(-4)$ & $1.2(-4)$ & $1.2(-4)$ & $1.8(-4)$ & $4.3(-4)$ \\
\hline $\operatorname{CO} J=11-10$ & $8.2(-5)$ & $8.9(-5)$ & $9.4(-$ & $1.6(-4)$ & $4.8(-4)$ \\
\hline $\mathrm{CO} J=12-11$ & $3.8(-5)$ & $4.3(-5)$ & $4.8(-5)$ & $1.1(-4)$ & $5.0(-4)$ \\
\hline $\mathrm{CO} J=13-12$ & $1.2(-5)$ & $1.4(-$ & $1.6(-$ & $5.1(-5)$ & $4.7(-4)$ \\
\hline $\mathrm{CO} J=14-13$ & $4.7(-$ & 5.2( & 5.7( & $1.8(-5)$ & $3.8(-4)$ \\
\hline $\mathrm{CO} J=17-16$ & $3.4(-6)$ & 3.4( & & $3.8(-6)$ & $5.8(-5)$ \\
\hline $\operatorname{CO} J=20-19$ & $(-6)$ & & & & $7.8(-6)$ \\
\hline $\mathrm{CO} J=24-23$ & $2.4(-$ & & & $2.2(-6)$ & $2.4(-6)$ \\
\hline $\mathrm{CO} J=30-29$ & $4.9(-7)$ & $4.9(-7)$ & $4.8(-7)$ & $4.4(-7)$ & $4.9(-7)$ \\
\hline $\mathrm{CO} J=35-34$ & $1.0(-7)$ & $1.0(-7)$ & $1.0(-7)$ & $9.9(-8)$ & $1.3(-7)$ \\
\hline${ }^{13} \mathrm{CO} J=1-0$ & 4.1(-8) & $4.1(-8)$ & $4.0(-8)$ & $3.6(-8)$ & $1.4(-8)$ \\
\hline${ }^{13} \mathrm{CO} J=2-1$ & $7.9(-7)$ & $7.9(-7)$ & 7.9(-7) & 7.6(-7) & $3.7(-7)$ \\
\hline${ }^{13} \mathrm{CO} \mathrm{J}=3-2$ & $3.4(-6)$ & $3.4(-6)$ & $3.4(-6)$ & $3.5(-6)$ & $2.2(-6)$ \\
\hline${ }^{13} \mathrm{CO} \mathrm{J}=4-3$ & $8.4(-6)$ & $8.5(-6)$ & $8.5(-6)$ & $9.1(-6)$ & $7.0(-6)$ \\
\hline${ }^{13} \mathrm{CO} \mathrm{J}=5-4$ & $1.5(-5)$ & $1.5(-5)$ & $1.5(-5)$ & $1.7(-5)$ & $1.5(-5)$ \\
\hline${ }^{13} \mathrm{CO} J=6-5$ & $2.2(-5)$ & $2.2(-5)$ & $2.2(-5)$ & $2.6(-5)$ & $2.7(-5)$ \\
\hline${ }^{13} \mathrm{CO} \mathrm{J}=7-6$ & $2.5(-5)$ & $2.6(-5)$ & $2.6(-5)$ & $3.3(-5)$ & $3.9(-5)$ \\
\hline${ }^{13} \mathrm{CO} J=8-7$ & $2.3(-5)$ & $2.4(-5)$ & $2.5(-5)$ & $3.4(-5)$ & $5.0(-5)$ \\
\hline${ }^{13} \mathrm{CO} J=9-8$ & $1.6(-5)$ & $1.7(-5)$ & $1.8(-5)$ & $2.8(-5)$ & $5.6(-5)$ \\
\hline${ }^{13} \mathrm{CO} J=10-9$ & $8.3(-6)$ & $9.1(-6)$ & $9.7(-6)$ & $1.8(-5)$ & $5.5(-5)$ \\
\hline${ }^{13} \mathrm{CO} J=11-10$ & $3.4(-6)$ & $3.8(-6)$ & $4.2(-6)$ & $9.6(-6)$ & $4.7(-5)$ \\
\hline${ }^{13} \mathrm{CO} J=12-11$ & $1.2(-6)$ & $1.4(-6)$ & $1.5(-6)$ & $4.2(-6)$ & $3.6(-5)$ \\
\hline${ }^{13} \mathrm{CO} J=13-12$ & $4.0(-7)$ & $4.4(-7)$ & $5.0(-7)$ & $1.6(-6)$ & $2.4(-5)$ \\
\hline${ }^{13} \mathrm{CO} J=14-13$ & $1.5(-7)$ & $1.6(-7)$ & $1.8(-7)$ & $5.7(-7)$ & $1.4(-5)$ \\
\hline
\end{tabular}


R. Meijerink et al.: Star formation in extreme environments

Table 7. Line intensities for model set $1 \mathrm{~b}$.

\begin{tabular}{|c|c|c|c|c|c|}
\hline \multirow[t]{2}{*}{ Line } & \multicolumn{5}{|c|}{ Cosmic ray rate $\left(\mathrm{s}^{-1}\right)$} \\
\hline & $5(-17)$ & $5(-16)$ & $5(-15)$ & $5(-14)$ & $5(-13)$ \\
\hline \multicolumn{6}{|c|}{ Line intensities $\left(\mathrm{erg} \mathrm{s}^{-1} \mathrm{~cm}^{-2} \mathrm{sr}^{-1}\right)$} \\
\hline$\overline{[\mathrm{CII}]} 158 \mu \mathrm{m}$ & $1.1(-3)$ & $1.1(-3)$ & $1.1(-3)$ & $1.2(-3)$ & $1.3(-3)$ \\
\hline$[\mathrm{CI}] 610 \mu \mathrm{m}$ & $3.4(-6)$ & $3.6(-6)$ & $3.9(-6)$ & $4.9(-6)$ & $7.3(-6)$ \\
\hline [CI] $370 \mu \mathrm{m}$ & $2.4(-5)$ & $2.5(-5)$ & $2.8(-5)$ & $3.4(-5)$ & $5.2(-5)$ \\
\hline [OI] $63 \mu \mathrm{m}$ & $9.3(-2)$ & $9.4(-2)$ & $9.4(-2)$ & $9.8(-2)$ & $1.1(-1)$ \\
\hline [OI] $146 \mu \mathrm{m}$ & $3.7(-3)$ & $3.7(-3)$ & $3.8(-3)$ & $3.9(-3)$ & $4.1(-3)$ \\
\hline [NII] $205 \mu \mathrm{m}$ & $4.7(-11)$ & $4.7(-10)$ & $5.0(-9)$ & $5.7(-8)$ & $4.3(-7)$ \\
\hline [NII] $122 \mu \mathrm{m}$ & $7.2(-10)$ & $7.2(-9)$ & $7.7(-8)$ & $8.8(-7)$ & $6.7(-6)$ \\
\hline $\mathrm{H}_{3}^{+} 95 \mu \mathrm{m}$ & $3.6(-9)$ & $3.8(-8)$ & $3.6(-7)$ & $2.8(-6)$ & $6.0(-6)$ \\
\hline $\mathrm{HCN} J=1-0$ & $3.1(-8)$ & $5.8(-8)$ & $1.2(-7)$ & $1.3(-7)$ & $2.0(-8)$ \\
\hline $\mathrm{HCN} J=2-1$ & $2.9(-7)$ & $4.3(-7)$ & $6.7(-7)$ & $7.4(-7)$ & $2.8(-7)$ \\
\hline $\mathrm{HCN} J=3-2$ & $8.3(-7)$ & $1.2(-6)$ & $1.9(-6)$ & $2.0(-6)$ & $8.1(-7)$ \\
\hline $\mathrm{HCN} J=4-3$ & $1.6(-6)$ & $2.6(-6)$ & $4.1(-6)$ & $4.4(-6)$ & $1.5(-6)$ \\
\hline $\mathrm{HCN} J=5-4$ & $2.0(-6)$ & $4.2(-6)$ & $7.4(-6)$ & $8.1(-6)$ & $2.0(-6)$ \\
\hline $\mathrm{HCN} J=6-5$ & $1.8(-6)$ & $5.2(-6)$ & $1.2(-5)$ & $1.3(-5)$ & $1.9(-6)$ \\
\hline $\mathrm{HCN} J=7-6$ & $1.5(-6)$ & $4.6(-6)$ & $1.5(-5)$ & $1.8(-5)$ & $1.6(-6)$ \\
\hline $\mathrm{HNC} J=1-0$ & $2.2(-8)$ & $3.0(-8)$ & $5.5(-8)$ & $6.0(-8)$ & $2.2(-8)$ \\
\hline $\mathrm{HNC} J=2-1$ & $2.3(-7)$ & $2.9(-7)$ & $4.3(-7)$ & $4.7(-7)$ & $2.8(-7)$ \\
\hline HNC $J=3-2$ & $6.5(-7)$ & $8.2(-7)$ & $1.2(-6)$ & $1.3(-6)$ & $8.1(-7)$ \\
\hline HNC $J=4-3$ & $1.1(-6)$ & $1.5(-6)$ & $2.5(-6)$ & $2.8(-6)$ & $1.5(-6)$ \\
\hline HNC $J=5-4$ & $1.2(-6)$ & $2.0(-6)$ & $4.0(-6)$ & $4.5(-6)$ & $1.9(-6)$ \\
\hline $\mathrm{HNC} J=6-5$ & $1.1(-6)$ & $1.8(-6)$ & $4.7(-6)$ & $5.6(-6)$ & $1.8(-6)$ \\
\hline $\mathrm{HNC} J=7-6$ & $9.2(-7)$ & $1.5(-6)$ & $3.8(-6)$ & $4.9(-6)$ & $1.5(-6)$ \\
\hline $\mathrm{HCO}^{+} J=1-0$ & $1.9(-8)$ & $1.4(-7)$ & $3.3(-7)$ & $5.5(-7)$ & $1.9(-7)$ \\
\hline $\mathrm{HCO}^{+} J=2-1$ & $3.8(-7)$ & $1.7(-6)$ & $2.9(-6)$ & $3.9(-6)$ & $2.5(-6)$ \\
\hline $\mathrm{HCO}^{+} J=3-2$ & $1.3(-6)$ & $4.7(-6)$ & $6.5(-6)$ & $8.2(-6)$ & $6.6(-6)$ \\
\hline $\mathrm{HCO}^{+} J=4-3$ & $2.7(-6)$ & $9.5(-6)$ & $1.3(-5)$ & $1.5(-5)$ & $1.3(-5)$ \\
\hline $\mathrm{HCO}^{+} J=5-4$ & $4.1(-6)$ & $1.7(-5)$ & $2.3(-5)$ & $2.7(-5)$ & $2.3(-5)$ \\
\hline $\mathrm{HCO}^{+} J=6-5$ & $4.9(-6)$ & $2.7(-5)$ & $3.8(-5)$ & $4.5(-5)$ & $3.7(-5)$ \\
\hline $\mathrm{HCO}^{+} J=7-6$ & $4.5(-6)$ & $3.9(-5)$ & $5.9(-5)$ & $7.1(-5)$ & $5.5(-5)$ \\
\hline $\mathrm{CO} J=1-0$ & $4.2(-7)$ & $4.1(-7)$ & $4.1(-7)$ & $4.0(-7)$ & $3.6(-7)$ \\
\hline $\mathrm{CO} J=2-1$ & $6.1(-6)$ & $6.1(-6)$ & $6.2(-6)$ & $6.1(-6)$ & $5.8(-6)$ \\
\hline $\mathrm{CO} J=3-2$ & $2.5(-5)$ & $2.5(-5)$ & $2.5(-5)$ & $2.5(-5)$ & $2.4(-5)$ \\
\hline $\mathrm{CO} J=4-3$ & $6.3(-5)$ & $6.3(-5)$ & $6.4(-5)$ & $6.4(-5)$ & $6.4(-5)$ \\
\hline $\mathrm{CO} J=5-4$ & $1.3(-4)$ & $1.3(-4)$ & $1.3(-4)$ & $1.3(-4)$ & $1.3(-4)$ \\
\hline $\mathrm{CO} J=6-5$ & $2.2(-4)$ & $2.2(-4)$ & $2.3(-4)$ & $2.3(-4)$ & $2.3(-4)$ \\
\hline $\mathrm{CO} J=7-6$ & $3.5(-4)$ & $3.6(-4)$ & $3.6(-4)$ & $3.6(-4)$ & $3.7(-4)$ \\
\hline $\mathrm{CO} J=8-7$ & $5.2(-4)$ & $5.2(-4)$ & $5.3(-4)$ & $5.3(-4)$ & $5.5(-4)$ \\
\hline $\mathrm{CO} J=9-8$ & $7.1(-4)$ & $7.3(-4)$ & $7.3(-4)$ & $7.3(-4)$ & $7.7(-4)$ \\
\hline $\mathrm{CO} J=10-9$ & $9.4(-4)$ & $9.6(-4)$ & $9.7(-4)$ & $9.7(-4)$ & $1.0(-3)$ \\
\hline $\mathrm{CO} J=11-10$ & $1.2(-3)$ & $1.2(-3)$ & $1.2(-3)$ & $1.2(-3)$ & $1.3(-3)$ \\
\hline $\mathrm{CO} J=12-11$ & $1.5(-3)$ & $1.5(-3)$ & $1.5(-3)$ & $1.5(-3)$ & $1.6(-3)$ \\
\hline $\mathrm{CO} J=13-12$ & $1.7(-3)$ & $1.8(-3)$ & $1.8(-3)$ & $1.7(-3)$ & $1.8(-3)$ \\
\hline $\mathrm{CO} J=14-13$ & $2.0(-3)$ & $2.0(-3)$ & $2.0(-3)$ & $2.0(-3)$ & $2.1(-3)$ \\
\hline $\mathrm{CO} J=17-16$ & $2.2(-3)$ & $2.4(-3)$ & $2.3(-3)$ & $2.2(-3)$ & $2.3(-3)$ \\
\hline $\mathrm{CO} J=20-19$ & $9.1(-4)$ & $1.1(-3)$ & $1.0(-3)$ & $8.7(-4)$ & $1.2(-3)$ \\
\hline $\mathrm{CO} J=24-23$ & $2.7(-5)$ & $3.7(-5)$ & $3.1(-5)$ & $2.6(-5)$ & $5.5(-5)$ \\
\hline $\mathrm{CO} J=30-29$ & $8.0(-7)$ & $8.1(-7)$ & $7.8(-7)$ & $7.2(-7)$ & $7.8(-7)$ \\
\hline $\mathrm{CO} J=35-34$ & $1.7(-7)$ & $1.7(-7)$ & $1.7(-7)$ & $1.6(-7)$ & $1.9(-7)$ \\
\hline${ }^{13} \mathrm{CO} J=1-0$ & $1.5(-8)$ & $1.4(-8)$ & $1.4(-8)$ & $1.4(-8)$ & $1.1(-8)$ \\
\hline${ }^{13} \mathrm{CO} J=2-1$ & $4.3(-7)$ & $4.2(-7)$ & $4.2(-7)$ & $4.0(-7)$ & $3.2(-7)$ \\
\hline${ }^{13} \mathrm{CO} J=3-2$ & $2.9(-6)$ & $2.8(-6)$ & $2.8(-6)$ & $2.7(-6)$ & $2.2(-6)$ \\
\hline${ }^{13} \mathrm{CO} J=4-3$ & $1.0(-5)$ & $1.0(-5)$ & $1.0(-5)$ & $9.6(-6)$ & $7.9(-6)$ \\
\hline${ }^{13} \mathrm{CO} J=5-4$ & $2.6(-5)$ & $2.5(-5)$ & $2.5(-5)$ & $2.4(-5)$ & $2.0(-5)$ \\
\hline${ }^{13} \mathrm{CO} J=6-5$ & $5.1(-5)$ & $5.0(-5)$ & $5.0(-5)$ & $4.8(-5)$ & $4.1(-5)$ \\
\hline${ }^{13} \mathrm{CO} J=7-6$ & $8.5(-5)$ & $8.5(-5)$ & $8.5(-5)$ & $8.1(-5)$ & $7.0(-5)$ \\
\hline${ }^{13} \mathrm{CO} J=8-7$ & $1.3(-4)$ & $1.3(-4)$ & $1.3(-4)$ & $1.2(-4)$ & $1.1(-4)$ \\
\hline${ }^{13} \mathrm{CO} J=9-8$ & $1.7(-4)$ & $1.7(-4)$ & $1.7(-4)$ & $1.7(-4)$ & $1.5(-4)$ \\
\hline${ }^{13} \mathrm{CO} J=10-9$ & $2.1(-4)$ & $2.1(-4)$ & $2.1(-4)$ & $2.0(-4)$ & $1.9(-4)$ \\
\hline${ }^{13} \mathrm{CO} J=11-10$ & $2.4(-4)$ & $2.5(-4)$ & $2.4(-4)$ & $2.3(-4)$ & $2.2(-4)$ \\
\hline${ }^{13} \mathrm{CO} J=12-11$ & $2.5(-4)$ & $2.6(-4)$ & $2.5(-4)$ & $2.4(-4)$ & $2.3(-4)$ \\
\hline${ }^{13} \mathrm{CO} J=13-12$ & $2.4(-4)$ & $2.5(-4)$ & $2.4(-4)$ & $2.3(-4)$ & $2.4(-4)$ \\
\hline${ }^{13} \mathrm{CO} J=14-13$ & $2.0(-4)$ & $2.2(-4)$ & $2.1(-4)$ & $2.0(-4)$ & $2.2(-4)$ \\
\hline
\end{tabular}

Table 8. Line intensities for model set 1c.

\begin{tabular}{|c|c|c|c|c|c|}
\hline \multirow[t]{2}{*}{ Line } & \multicolumn{5}{|c|}{ Cosmic ray rate $\left(\mathrm{s}^{-1}\right)$} \\
\hline & $5(-17)$ & $5(-16)$ & $5(-15)$ & $5(-14)$ & $5(-13)$ \\
\hline \multicolumn{6}{|c|}{ Line intensities $\left(\mathrm{erg} \mathrm{s}^{-1} \mathrm{~cm}^{-2} \mathrm{sr}^{-1}\right)$} \\
\hline$\overline{[\mathrm{CII}] 158 \mu \mathrm{m}}$ & $1.1(-3)$ & $1.1(-3)$ & $1.1(-3)$ & $1.1(-3)$ & $1.3(-3)$ \\
\hline [CI] $610 \mu \mathrm{m}$ & $8.3(-7)$ & $1.3(-6)$ & $2.5(-6)$ & $3.8(-6)$ & $7.7(-6)$ \\
\hline [CI] $370 \mu \mathrm{m}$ & $7.1(-6)$ & $1.1(-5)$ & $2.1(-5)$ & $3.2(-5)$ & $6.3(-5)$ \\
\hline [OI] $63 \mu \mathrm{m}$ & $1.1(-1)$ & 1.1(-1) & $1.1(-1)$ & $1.3(-1)$ & $1.5(-1)$ \\
\hline [OI] $146 \mu \mathrm{m}$ & $3.9(-3)$ & $3.9(-3)$ & 4.1(-3) & $5.4(-3)$ & $6.7(-3)$ \\
\hline [NII] $205 \mu \mathrm{m}$ & $7.3(-11)$ & $7.3(-10)$ & 7.5(-9) & 7.1(-8) & $4.7(-7)$ \\
\hline [NII] $122 \mu \mathrm{m}$ & $1.1(-9)$ & $1.1(-8)$ & $1.1(-7)$ & $1.1(-6)$ & 7.4(-6) \\
\hline $\mathrm{H}_{3}^{+} 95 \mu \mathrm{m}$ & $1.8(-9)$ & $1.7(-8)$ & $1.8(-7)$ & $2.1(-6)$ & $9.9(-6)$ \\
\hline $\mathrm{HCN} J=1-0$ & $3.9(-5)$ & $4.0(-5)$ & $2.2(-5)$ & $4.7(-6)$ & $1.8(-7)$ \\
\hline $\mathrm{HCN} J=2-1$ & $2.1(-5)$ & $2.0(-5)$ & $1.7(-5)$ & $9.5(-6)$ & $2.7(-6)$ \\
\hline $\mathrm{HCN} J=3-2$ & $1.8(-5)$ & $1.9(-5)$ & $1.8(-5)$ & $1.4(-5)$ & $4.1(-6)$ \\
\hline $\mathrm{HCN} J=4-3$ & $3.0(-5)$ & $3.1(-5)$ & $3.0(-5)$ & $2.6(-5)$ & $1.2(-5)$ \\
\hline $\mathrm{HCN} J=5-4$ & $5.2(-5)$ & $5.3(-5)$ & $5.3(-5)$ & $4.4(-5)$ & $2.0(-5)$ \\
\hline $\mathrm{HCN} J=6-5$ & $9.1(-5)$ & $9.3(-5)$ & $9.3(-$ & $7.5(-5)$ & $3.5(-5)$ \\
\hline $\mathrm{HCN} J=7-6$ & $1.5(-4)$ & $1.6(-4)$ & $1.6(-4)$ & $1.2(-4)$ & $5.4(-5)$ \\
\hline HNC $J=1-0$ & $7.9(-7)$ & $6.0(-7)$ & & $1.2(-7)$ & 1.7( \\
\hline HNC $J=2-1$ & $3.3(-6)$ & $2.9(-6)$ & $2.4(-$ & $1.1(-6)$ & $3.0(-7)$ \\
\hline HNC $J=3-2$ & $6.4(-6)$ & $5.9(-6)$ & $5.2(-$ & 4.4(-6) & $1.0(-6)$ \\
\hline HNC $J=4-3$ & $1.3(-5)$ & $1.2(-5)$ & $1.1(-5)$ & 7.4(-6) & $2.1(-6)$ \\
\hline HNC $J=5-4$ & $2.4(-5)$ & $2.2(-5)$ & $2.0(-5)$ & $1.3(-5)$ & $3.1(-6)$ \\
\hline HNC $J=6-5$ & $4.1(-5)$ & $3.8(-5)$ & $3.4(-5)$ & $2.0(-5)$ & $3.4(-6)$ \\
\hline HNC $J=7-6$ & $6.8(-5)$ & $6.2(-5)$ & $5.5(-5)$ & $3.0(-5)$ & $3.3(-6)$ \\
\hline $\mathrm{HCO}^{+} J=1-0$ & $4.9(-9)$ & $1.0(-8)$ & $3.9(-8)$ & $1.9(-7)$ & $4.9(-7)$ \\
\hline $\mathrm{HCO}^{+} J=2-1$ & $1.4(-7)$ & $2.7(-7)$ & $8.8(-7)$ & $3.1(-6)$ & $7.6(-6)$ \\
\hline $\mathrm{HCO}^{+} J=3-2$ & $6.6(-7)$ & $1.2(-6)$ & $3.2(-6)$ & $8.7(-6)$ & $1.7(-5)$ \\
\hline $\mathrm{HCO}^{+} J=4-3$ & $1.7(-6)$ & $2.7(-6)$ & $6.8(-6)$ & $1.7(-5)$ & $3.1(-5)$ \\
\hline $\mathrm{HCO}^{+} J=5-4$ & $2.7(-6)$ & $4.2(-6)$ & $1.2(-5)$ & $3.0(-5)$ & $5.0(-5)$ \\
\hline $\mathrm{HCO}^{+} J=6-5$ & $3.2(-6)$ & $5.1(-6)$ & $1.7(-5)$ & $4.7(-5)$ & $7.9(-5)$ \\
\hline $\mathrm{HCO}^{+} J=7-6$ & $3.3(-6)$ & 5.2( & $2.2(-$ & $7.0(-$ & \\
\hline $\mathrm{CO} J=1-0$ & $2.1(-7)$ & $2.3(-7)$ & $2.7(-7)$ & $2.9(-7)$ & $2.3(-7)$ \\
\hline $\mathrm{CO} J=2-1$ & $5.5(-6)$ & $5.9(-6)$ & $6.7(-6)$ & $6.9(-6)$ & $5.7(-6)$ \\
\hline $\mathrm{CO} J=3-2$ & $3.1(-5)$ & $3.3(-5)$ & $3.6(-5)$ & $3.7(-5)$ & $3.2(-5)$ \\
\hline $\mathrm{CO} J=4-3$ & $9.6(-5)$ & $1.0(-4)$ & $1.1(-4)$ & $1.1(-4)$ & $9.8(-5)$ \\
\hline $\mathrm{CO} J=5-4$ & $2.2(-4)$ & $2.2(-4)$ & $2.4(-4)$ & $2.4(-4)$ & $2.2(-4)$ \\
\hline $\mathrm{CO} J=6-5$ & $4.1(-4)$ & $4.2(-4)$ & $4.4(-4)$ & $4.5(-4)$ & $4.2(-4)$ \\
\hline $\mathrm{CO} J=7-6$ & $6.8(-4)$ & $7.0(-4)$ & 7.3(-4) & $7.5(-4)$ & $7.0(-4)$ \\
\hline $\mathrm{CO} J=8-7$ & $1.0(-3)$ & $1.1(-3)$ & $1.1(-3)$ & $1.2(-3)$ & $1.1(-3)$ \\
\hline $\mathrm{CO} J=9-8$ & $1.5(-3)$ & $1.5(-3)$ & $1.6(-3)$ & $1.6(-3)$ & $1.6(-3)$ \\
\hline $\operatorname{CO} J=10-9$ & $2.0(-3)$ & $2.1(-3)$ & $2.2(-3)$ & $2.2(-3)$ & $2.1(-3)$ \\
\hline $\mathrm{CO} J=11-10$ & $2.6(-3)$ & $2.7(-3)$ & $2.9(-3)$ & $2.9(-3)$ & $2.8(-3)$ \\
\hline $\operatorname{CO} J=12-11$ & $3.3(-3)$ & $3.4(-3)$ & $3.6(-3)$ & $3.7(-3)$ & $3.6(-3)$ \\
\hline $\mathrm{CO} J=13-12$ & $4.0(-3)$ & 4.1(-3) & $4.4(-3)$ & $4.5(-3)$ & $4.5(-3)$ \\
\hline $\mathrm{CO} J=14-13$ & & $4.9(-$ & & $5.4(-3)$ & $5.4(-3)$ \\
\hline $\mathrm{CO} J=17-16$ & $6.5(-3)$ & $6.8(-3)$ & 7.3(-3) & $7.6(-3)$ & $8.1(-3)$ \\
\hline $\operatorname{CO} J=20-19$ & $6.6(-3)$ & $7.0(-3)$ & $7.7(-3)$ & $8.3(-3)$ & $9.6(-3)$ \\
\hline $\mathrm{CO} J=24-23$ & $1.8(-3)$ & $2.1(-3)$ & $2.9(-3)$ & $3.7(-3)$ & $6.3(-3)$ \\
\hline $\mathrm{CO} J=30-29$ & $3.7(-5)$ & $4.2(-5)$ & $5.4(-5)$ & $6.9(-5)$ & $2.1(-4)$ \\
\hline $\mathrm{CO} J=35-34$ & $3.1(-6)$ & $3.2(-6)$ & $3.5(-6)$ & $3.6(-6)$ & $7.6(-6)$ \\
\hline${ }^{13} \mathrm{CO} J=1-0$ & $5.5(-9)$ & $6.1(-9)$ & $7.2(-9)$ & $7.6(-9)$ & $5.6(-9)$ \\
\hline${ }^{13} \mathrm{CO} J=2-1$ & $1.7(-7)$ & $1.9(-8)$ & $2.3(-7)$ & $2.4(-7)$ & $1.7(-7)$ \\
\hline${ }^{13} \mathrm{CO} J=3-2$ & $1.2(-6)$ & $1.4(-6)$ & $1.6(-6)$ & $1.7(-6)$ & $1.3(-6)$ \\
\hline${ }^{13} \mathrm{CO} J=4-3$ & $5.0(-6)$ & $5.5(-6)$ & $6.5(-6)$ & $6.8(-6)$ & $5.0(-6)$ \\
\hline${ }^{13} \mathrm{CO} J=5-4$ & $1.4(-5)$ & $1.5(-5)$ & $1.8(-5)$ & $1.9(-5)$ & $1.4(-5)$ \\
\hline${ }^{13} \mathrm{CO} J=6-5$ & $3.2(-5)$ & $3.5(-5)$ & $4.1(-5)$ & $4.3(-5)$ & $3.2(-5)$ \\
\hline${ }^{13} \mathrm{CO} J=7-6$ & $6.1(-5)$ & $6.6(-5)$ & $7.8(-5)$ & $8.2(-5)$ & $6.3(-5)$ \\
\hline${ }^{13} \mathrm{CO} J=8-7$ & $1.0(-4)$ & $1.1(-4)$ & $1.3(-4)$ & $1.4(-4)$ & $1.1(-4)$ \\
\hline${ }^{13} \mathrm{CO} \mathrm{J}=9-8$ & $1.6(-4)$ & $1.7(-4)$ & $2.0(-4)$ & $2.1(-4)$ & $1.7(-4)$ \\
\hline${ }^{13} \mathrm{CO} J=10-9$ & $2.2(-4)$ & $2.4(-4)$ & $2.8(-4)$ & $3.0(-4)$ & $2.4(-4)$ \\
\hline${ }^{13} \mathrm{CO} \mathrm{J}=11-10$ & $2.9(-4)$ & $3.1(-4)$ & $3.6(-4)$ & $3.9(-4)$ & $3.3(-4)$ \\
\hline${ }^{13} \mathrm{CO} J=12-11$ & $3.5(-4)$ & $3.8(-4)$ & 4.4(-4) & $4.8(-4)$ & $4.2(-4)$ \\
\hline${ }^{13} \mathrm{CO} J=13-12$ & $4.0(-4)$ & $4.3(-4)$ & $5.1(-4)$ & $5.5(-4)$ & $5.1(-4)$ \\
\hline${ }^{13} \mathrm{CO} J=14-13$ & $4.2(-4)$ & $4.6(-4)$ & $5.4(-4)$ & $6.0(-4)$ & $5.9(-4)$ \\
\hline
\end{tabular}


Table 9. Line intensities for model set 2 .

\begin{tabular}{|c|c|c|c|c|c|}
\hline \multirow[t]{2}{*}{ Line } & \multicolumn{5}{|c|}{ Cosmic ray rate $\left(\mathrm{s}^{-1}\right)$} \\
\hline & $5(-17)$ & $5(-16)$ & $5(-15)$ & $5(-14)$ & $5(-13)$ \\
\hline \multicolumn{6}{|c|}{ Line intensities $\left(\mathrm{erg} \mathrm{s}^{-1} \mathrm{~cm}^{-2} \mathrm{sr}^{-1}\right)$} \\
\hline [CII] $158 \mu \mathrm{m}$ & $4.4(-4)$ & $4.7(-4)$ & $5.8(-4)$ & $8.6(-4)$ & $1.2(-3)$ \\
\hline [CI] $610 \mu \mathrm{m}$ & $3.6(-6)$ & $4.6(-6)$ & $9.7(-6)$ & $6.6(-6)$ & $2.8(-6)$ \\
\hline [CI] $370 \mu \mathrm{m}$ & $1.0(-5)$ & $1.3(-5)$ & $3.5(-5)$ & $3.0(-5)$ & $1.5(-5)$ \\
\hline [OI] $63 \mu \mathrm{m}$ & $4.5(-4)$ & $6.4(-4)$ & $1.3(-3)$ & $2.4(-3)$ & $2.9(-3)$ \\
\hline [OI] $146 \mu \mathrm{m}$ & $5.5(-6)$ & $7.0(-6)$ & $1.1(-5)$ & $2.1(-5)$ & $3.1(-5)$ \\
\hline [NII] $205 \mu \mathrm{m}$ & $6.6(-9)$ & $5.3(-8)$ & $3.7(-7)$ & $2.1(-6)$ & $7.6(-6)$ \\
\hline [NII] $122 \mu \mathrm{m}$ & $4.2(-7)$ & $7.2(-7)$ & $5.5(-6)$ & $3.3(-5)$ & $1.1(-4)$ \\
\hline $\mathrm{H}_{3}^{+} 95 \mu \mathrm{m}$ & $4.7(-10)$ & $7.0(-9)$ & $3.2(-8)$ & $2.0(-8)$ & $3.6(-9)$ \\
\hline $\mathrm{CO} J=1-0$ & $7.6(-8)$ & $1.3(-7)$ & $5.0(-8)$ & $2.8(-9)$ & $5.2(-12)$ \\
\hline $\mathrm{CO} J=2-1$ & $4.0(-7)$ & $6.5(-7)$ & $4.4(-7)$ & $5.3(-8)$ & $1.2(-10)$ \\
\hline $\mathrm{CO} J=3-2$ & $1.5(-6)$ & $2.0(-6)$ & $1.1(-6)$ & $1.4(-7)$ & $3.6(-10)$ \\
\hline $\mathrm{CO} J=4-3$ & $4.7(-6)$ & $5.7(-6)$ & $1.4(-6)$ & $1.4(-7)$ & $4.2(-10)$ \\
\hline $\mathrm{CO} J=5-4$ & $1.2(-5)$ & $1.4(-5)$ & 7.6(-7) & $8.9(-8)$ & $2.9(-10)$ \\
\hline $\mathrm{CO} J=6-5$ & $2.2(-5)$ & $2.6(-5)$ & $2.7(-7)$ & $4.1(-8)$ & $1.6(-10)$ \\
\hline $\mathrm{CO} J=7-6$ & $3.2(-5)$ & $4.1(-5)$ & $7.5(-8)$ & $1.6(-8)$ & $7.0(-11)$ \\
\hline $\mathrm{CO} J=8-7$ & $3.4(-5)$ & $5.3(-5)$ & $1.9(-8)$ & $5.3(-9)$ & $2.8(-11)$ \\
\hline $\mathrm{CO} J=9-8$ & $2.3(-5)$ & $5.1(-5)$ & $4.4(-9)$ & $1.6(-9)$ & $1.1(-11)$ \\
\hline $\operatorname{CO} J=10-9$ & $2.9(-6)$ & $2.7(-5)$ & $1.1(-9)$ & $4.9(-10)$ & $4.3(-12)$ \\
\hline $\operatorname{CO} J=11-10$ & $7.2(-9)$ & $1.8(-6)$ & $3.4(-10)$ & $1.5(-10)$ & $2.0(-12)$ \\
\hline $\operatorname{CO} J=12-11$ & $5.0(-12)$ & $4.0(-9)$ & $1.1(-10)$ & $5.2(-11)$ & $1.1(-12)$ \\
\hline $\mathrm{CO} J=13-12$ & $3.6(-13)$ & $4.3(-11)$ & $4.0(-11)$ & $1.9(-11)$ & $6.5(-13)$ \\
\hline $\mathrm{CO} J=14-13$ & $1.0(-13)$ & $2.1(-12)$ & $1.2(-11)$ & $5.8(-12)$ & $1.8(-13)$ \\
\hline${ }^{13} \mathrm{CO} J=1-0$ & $3.1(-8)$ & $4.6(-8)$ & $1.6(-9)$ & $5.1(-11)$ & $9.1(-14)$ \\
\hline${ }^{13} \mathrm{CO} J=2-1$ & $1.6(-7)$ & $2.6(-7)$ & $2.5(-8)$ & $1.2(-9)$ & $2.4(-12)$ \\
\hline${ }^{13} \mathrm{CO} J=3-2$ & $3.3(-7)$ & $6.4(-7)$ & $5.3(-8)$ & $3.9(-9)$ & $9.5(-12)$ \\
\hline${ }^{13} \mathrm{CO} J=4-3$ & $2.0(-7)$ & $7.9(-7)$ & $4.6(-8)$ & $5.0(-9)$ & $1.4(-11)$ \\
\hline${ }^{13} \mathrm{CO} J=5-4$ & $2.0(-8)$ & $2.5(-7)$ & $2.6(-8)$ & $3.9(-9)$ & $1.2(-11)$ \\
\hline${ }^{13} \mathrm{CO} J=6-5$ & $1.9(-9)$ & $4.4(-8)$ & $1.1(-8)$ & $2.3(-9)$ & $8.2(-12)$ \\
\hline${ }^{13} \mathrm{CO} J=7-6$ & $1.2(-10)$ & $7.5(-9)$ & $4.4(-9)$ & $1.2(-9)$ & $4.7(-12)$ \\
\hline${ }^{13} \mathrm{CO} J=8-7$ & $9.8(-12)$ & $1.1(-9)$ & $1.5(-9)$ & $5.2(-10)$ & $2.4(-12)$ \\
\hline
\end{tabular}

$C O$ and ${ }^{13} \mathrm{CO}$ : in the high density models, there is very little response when increasing the cosmic ray flux. Fluxes are boosted, when mechanical heating plays an important role in the energy budget of the gas, but, in contrast to the $\mathrm{HCN}$ and $\mathrm{HNC}$ lines, it only affects high- $J$ transitions. When ${ }^{13} \mathrm{CO}$ line fluxes are also available, mechanical heating effects are potentially also seen in the lower- $J$ transitions $(J \lesssim 3)$. The $\mathrm{CO}$ to ${ }^{13} \mathrm{CO}$ line ratio increases, indicative of smaller optical depths, while CO fluxes only decrease by a factor of 2 .

\section{Key diagnostics}

The aim of this paper is to identify potential line diagnostics that can be used to trace an enhanced cosmic-ray radiation field and mechanical heating in the presence of starformation such as the central regions of Arp 220 and NGC 253. One of the remarkable results is that many commonly observed lines, such as, the [OI] $63 \mu \mathrm{m}$, [CI] $609 \mu \mathrm{m}$, [CII] $158 \mu \mathrm{m}$, and low- $J$ CO lines, show very moderate responses to high cosmic ray rates and mechanical feedback, when the medium is already exposed to large amounts of UV. This is a very useful result, since these lines can serve as a reference point to other affected line fluxes.

\subsection{Tracers of mechanical heating}

Mechanical heating only increases the temperature of the gas, leaving the ionization fraction unaffected. Tracing this heating mechanism with molecules that contain activation barriers in their formation route is thus very useful. Lines of, e.g., $\mathrm{HCN}$ and $\mathrm{H}_{2} \mathrm{O}$ become stronger relative to the aforementioned

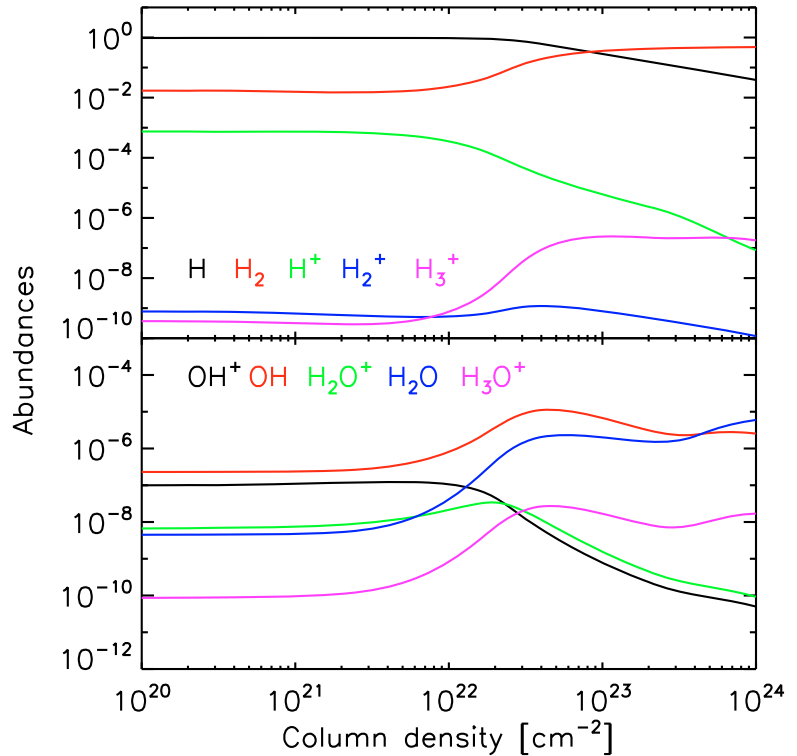

Fig. 8. Abundances of hydrogen and water chemistry for an XDR model

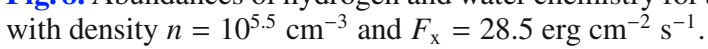

fine-structure lines, especially for the highest considered mechanical heating rate. It was already pointed out by Loenen et al. (2008) that the HCN/HNC line ratios increase when mechanical heating is important, since at high temperatures the $\mathrm{HNC}$ will be driven in to HCN (see also Sect. 2). Moreover, the HCN/CO line ratios also increase when mechanical heating effects are important, but the interpretation of an observed ratio is not straightforward, because the lines trace slightly different regions.

\subsection{Tracers of enhanced cosmic-ray rates}

The [NII] fine-structure lines show a very strong response to enhanced cosmic ray rates, independent of mechanical heating effects. The main concern with these lines, however, is that one has to distinguish the contributions arising from these CR exposed clouds and HII regions that also contribute a significant amount of [NII] emission in starforming environments.

It would be invaluable to study lines of species that trace the water chemistry, especially when the ionized water related species are considered. The $\mathrm{OH}$ to $\mathrm{H}_{2} \mathrm{O}$ column density ratio varies by over two to three orders of magnitude for the cosmic ray rates considered, from $\sim 5 \times 10^{-3}\left(\zeta=5.0 \times 10^{-17} \mathrm{~s}^{-1}\right)$ to $\sim 1-3$ $\left(\zeta=5.0 \times 10^{-13} \mathrm{~s}^{-1}\right)$ in the high density case, and $\sim 0.2$ to $\sim 400$ in the low density case. Hence, the $\mathrm{OH}$ lines are generally expected to be stronger relative to the water lines for higher cosmic ray rates. Figure 8 shows an XDR model of density $n=10^{5.5} \mathrm{~cm}^{-2}$, and radiation field $F_{\mathrm{X}}=28.5 \mathrm{erg} \mathrm{cm}^{-2} \mathrm{~s}^{-1}$ (a radiation field at a distance of $\sim 170 \mathrm{pc}$ from a typical AGN with $L_{\mathrm{X}}=10^{44} \mathrm{erg} / \mathrm{s}$ ). From this, we infer that the ratio varies between eight (integrated up to $\left.N_{\mathrm{H}}=3 \times 10^{22} \mathrm{~cm}^{-2}\right)$ and one $\left(N_{\mathrm{H}}=10^{24} \mathrm{~cm}^{-2}\right)$, so for very high $\mathrm{CR}$ rates, the ratios become comparable to that of a typical X-ray illuminated cloud.

van der Tak et al. (2008) already pointed out that the $\mathrm{H}_{3} \mathrm{O}^{+} / \mathrm{H}_{2} \mathrm{O}$ ratio is influenced by either cosmic rays or X-rays. The high density models exhibit variations over 1 to 2 orders of magnitude in the high density case. Unfortunately, the interpretation is not entirely unambiguous, since the $\mathrm{H}_{3} \mathrm{O}^{+}$abundance decreases for the highest $\mathrm{CR}$ rates. Clouds illuminated by 
high $\mathrm{CR}$ rates also have similar ratios as those exposed to $\mathrm{X}$ rays, namely $(1-6) \times 10^{-3}\left(\zeta=5 \times 10^{-14} \mathrm{~s}^{-1}\right)$ and $(5-10) \times 10^{-3}$ $\left(\zeta=5 \times 10^{-13} \mathrm{~s}^{-1}\right)$ for model set 1 , and in the range $(15-4) \times 10^{-3}$ (depending on the size of the cloud) for the XDR model shown in Fig. 8.

The current study has revealed that additional observations of $\mathrm{OH}^{+}$and $\mathrm{H}_{2} \mathrm{O}^{+}$might help in distinguishing very high $\mathrm{CR}$ rates from a typical XDR. The $\mathrm{OH}^{+}$and $\mathrm{H}_{2} \mathrm{O}^{+}$abundances are significantly higher for $\mathrm{CR}$ rates that are $10^{3}-10^{4}$ times higher than the accepted Milky Way value, but not as much as in the XDR. The $\mathrm{OH}^{+} / \mathrm{OH}$ and $\mathrm{H}_{2} \mathrm{O}^{+} / \mathrm{H}_{2} \mathrm{O}$ column density ratios can be as high as $(3-5) \times 10^{-4}$ and $(2-14) \times 10^{-4}$, respectively, compared to $(250-7.5) \times 10^{-4}$ and $(64-4) \times 10^{-3}$ $\left(N_{\mathrm{H}}=3 \times 10^{22}-10^{24} \mathrm{~cm}^{-2}\right)$. Thus, we can distinguish XDRs and regions with enhanced $\mathrm{CR}$ rates when all species are considered.

In this paper, no attempt has been made to model lines from these species. As already pointed out in e.g., González-Alfonso et al. (2008), the radiation transfer of $\mathrm{OH}$ and $\mathrm{H}_{2} \mathrm{O}$ involves the consideration of both collisions and radiation pumping, which is beyond the scope of this paper. In addition, $\mathrm{OH}^{+}$and $\mathrm{H}_{2} \mathrm{O}^{+}$ lines are not easily modeled. These species have formation and destruction timescales that are similar to those for excitation. Collisional cross-sections are also unavailable at the moment, and quantum mechanical calculations would be needed to obtain them.

\section{Outlook}

$\mathrm{OH}^{+}$and $\mathrm{H}_{2} \mathrm{O}^{+}$have already been detected in a number of sources:

- Van der Werf et al. (2010) detected $\mathrm{OH}^{+}$and $\mathrm{H}_{2} \mathrm{O}^{+}$emission lines in the ULIRG Mrk 231, which are about 30 percent of the strength of the $\mathrm{CO}(5-6)$ to $\mathrm{CO}(13-12)$ lines. The paper illustrates that these lines are caused by AGN activity in Mrk 231.

- In the Milky Way, $\mathrm{OH}^{+}$was detected in absorption toward Sagittarius B2 using the Atacama Pathfinder Experiment (APEX) by Wyrowski et al. (2010), who measured a column density of $2.4 \times 10^{15} \mathrm{~cm}^{-2}$. Ossenkopf et al. (2010) detected $\mathrm{H}_{2} \mathrm{O}^{+}$in absorption toward, NGC 6334, DR21, and Sgr B2, obtaining column densities of $7.2 \times 10^{12} \mathrm{~cm}^{-2}$, $2.3 \times 10^{13} \mathrm{~cm}^{-2}$, and $1.1 \times 10^{15} \mathrm{~cm}^{-2}$, respectively. These Galactic observations relate these species to the diffuse ISM.
Extensive modeling of the excitation of water-related species is very timely, since more and more observations will be available on a very short timeframe from observations with the recently lauched Herschel Space Telescope.

Acknowledgements. We thank Padelis Papadopoulos for useful discussions. We thank the anonymous referee for a careful reading of the manuscript and constructive comments.

\section{References}

Acero, F., Aharonian, F., Akhperjanian, A. G., et al. 2009, Science, 326, 1080

Asplund, M., Grevesse, N., \& Sauval, A. J. 2005, in Cosmic Abundances as Records of Stellar Evolution and Nucleosynthesis, ed. T. G. Barnes III, \& F. N. Bash, ASP Conf. Ser., 336, 25

Baan, W. A., Henkel, C., Loenen, A. F., Baudry, A., \& Wiklind, T. 2008, A\&A, 477, 747

Baan, W. A., Loenen, A. F., \& Spaans, M. 2010, A\&A, 516, A40

Bakes, E. L. O., \& Tielens, A. G. G. M. 1994, ApJ, 427, 822

Cazaux, S., \& Tielens, A. G. G. M. 2004, ApJ, 604, 222

Gao, Y., \& Solomon, P. M. 1999, ApJ, 512, L99

Gao, Y., Solomon, P. M., Downes, D., \& Radford, S. J. E. 1997, ApJ, 481, L35

González-Alfonso, E., Smith, H. A., Ashby, M. L. N., et al. 2008, ApJ, 675, 303

Hocuk, S., \& Spaans, M. 2010, A\&A, 522, A24

Hollenbach, D. J., \& Tielens, A. G. G. M. 1999, Rev. Mod. Phys., 71, 173

Jenkins, E. B. 2004, Origin and Evolution of the Elements, 336

Kaufman, M. J., Wolfire, M. G., Hollenbach, D. J., \& Luhman, M. L. 1999, ApJ, 527, 795

Klessen, R. S., Spaans, M., \& Jappsen, A. 2007, MNRAS, 374, L29

Leen, T. M., \& Graff, M. M. 1988, ApJ, 325, 411

Lepp, S., \& Dalgarno, A. 1996, A\&A, 306, L21

Loenen, A. F. 2009, Ph.D. Thesis, Kapteyn Astronomical Institute

Loenen, A. F., Spaans, M., Baan, W. A., \& Meijerink, R. 2008, A\&A, 488, L5

Lonsdale, C. J., Diamond, P. J., Thrall, H., Smith, H. E., \& Lonsdale, C. J. 2006, ApJ, 647, 185

Maloney, P. R., Hollenbach, D. J., \& Tielens, A. G. G. M. 1996, ApJ, 466, 561

Meijerink, R., \& Spaans, M. 2005, A\&A, 436, 397

Meijerink, R., Spaans, M., \& Israel, F. P. 2006, ApJ, 650, L103

Meijerink, R., Spaans, M., \& Israel, F. P. 2007, A\&A, 461, 793

Meijerink, R., Glassgold, A. E., \& Najita, J. R. 2008, ApJ, 676, 518

Ossenkopf, V., Müller, H. S. P., Lis, D. C., et al. 2010, A\&A, 518, L111

Pan, F., \& Oka, T. 1986, ApJ, 305, 518

Papadopoulos, P. P. 2010, ApJ, 720, 226

Rodríguez-Rico, C. A., Goss, W. M., Viallefond, F., et al. 2005, ApJ, 633, 198

Sakamoto, K., Aalto, S., Wilner, D. J., et al. 2009, ApJ, 700, L104

Sanders, D. B., \& Mirabel, I. F. 1996, ARA\&A, 34, 749

Smith, H. E., Lonsdale, C. J., Lonsdale, C. J., \& Diamond, P. J. 1998, ApJ, 493, L17

Soifer, B. T., Neugebauer, G., \& Houck, J. R. 1987, ARA\&A, 25, 187

van der Tak, F. F. S., \& van Dishoeck, E. F. 2000, A\&A, 358, L79

van der Tak, F. F. S., Aalto, S., \& Meijerink, R. 2008, A\&A, 477, L5

van der Werf, P. P., Isaak, K. G., Meijerink, R., et al. 2010, A\&A, 518, L42

Wyrowski, F., Menten, K. M., Güsten, R., \& Belloche, A. 2010, A\&A, 518, A26 